\title{
Reactivity and Synthetic Applications of 4,5-Dicyanopyridazine: An Overview ${ }^{\dagger}$
}

\section{Renzo Alfini, Marco Cecchi and Donatella Giomi *}

Laboratorio di Progettazione, Sintesi e Studio di Eterocicli Biologicamente Attivi (HeteroBioLab), Dipartimento di Chimica, Università di Firenze, Polo Scientifico e Tecnologico, Via della Lastruccia 3/13, I-50019 Sesto Fiorentino, Italy; E-Mail: renzo.alfini@unifi.it (R.A.)

* Author to whom correspondence should be addressed; E-Mail: donatella.giomi@unifi.it; Tel.: +39-0554573475; Fax: +39-0554573575.

+ Dedicated to Prof. Rodolfo Nesi on the occasion of his $70^{\text {th }}$ anniversary.

Received: 28 December 2009; in revised form: 12 February 2010 / Accepted: 5 March 2010 / Published: 12 March 2010

\begin{abstract}
Despite the poor reputation of electron-deficient pyridazines in intermolecular Hetero Diels-Alder (HDA) reactions, 4,5-dicyanopyridazine (DCP) showed a surprising reactivity as a heterocyclic azadiene in inverse electron-demand HDA processes with different dienophiles. The use of alkenes, alkynes and enamines as $2 \pi$ electron counterparts afforded dicyanocyclohexa-1,3-dienes and substituted phthalonitriles, respectively, while the use of suitable bis-dienophiles provides a general strategy for the one-pot synthesis of polycyclic carbo- and hetero-cage systems through pericyclic three-step homodomino processes. HDA reactions with heterocyclic dienophiles allowed direct benzoannelation: in particular, pyrrole and indole derivatives were converted to dicyano-indoles and -carbazoles. In addition an unprecedented reactivity of DCP as a very reactive heterocyclic electrophile at the C-4 carbon was also evidenced: by changing the experimental conditions, cyanopyrrolyl- and cyanoindolyl-pyridazines were obtained through reactions of pyrrole and indole systems as carbon nucleophiles in formal $\mathrm{S}_{\mathrm{N}} \mathrm{Ar} 2$ processes where a CN group of DCP acts as leaving group. Thus, careful control of the reaction conditions allows exploitation of both pathways for the synthesis of different classes of heterocyclic derivatives.
\end{abstract}


Keywords: pyridazine derivatives; Hetero Diels-Alder reactions; nucleophilic aromatic substitutions; cage compounds; phthalonitriles

\section{Introduction}

Pyridazine and its benzo derivatives have been known since the nineteenth century, but interest in these compounds was quite limited compared to other nitrogen heterocycles, like for instance the pyrimidines, because only a few examples of naturally occurring 1,2-diazines have been reported. Anyway, in the last decades, the biological activity exhibited by many synthetic derivatives has stimulated intensive research on this heterocyclic system [1-3].

This review article concerns a very specific domain in particular, being focused on the reactivity and synthetic applications of 4,5-dicyanopyridazine (DCP, $\mathbf{1}$ ), a pyridazine derivative first synthesized in 1968 but essentially only exploited in organic synthesis in the last fifteen years. According with the most significant aspects of reactivity of DCP, namely as heterocyclic electron-poor azadiene in inverse electron-demand Hetero Diels-Alder (HDA) reactions and heterocyclic electrophile in formal nucleophilic aromatic substitutions $\mathrm{S}_{\mathrm{N}} \mathrm{Ar}$, this review is organized into four parts concerning the synthesis of DCP (Section 2), Hetero Diels-Alder reactions (Section 3), nucleophilic aromatic substitutions (Section 4), and synthetic applications (Section 5).

\section{Syntheses of 4,5-Dicyanopyridazine (DCP)}

The synthesis of 4,5-dicyanopyridazine (1) was first accomplished in 1968 by Di Stefano and Castle [4] by dehydration of pyridazine-4,5-dicarboxamide, obtained from pyridazine-4,5-dicarboxylic acid, through the corresponding dimethylpyridazine-4,5-dicarboxylate (Scheme 1, condition a). In 1985 Heinisch and Lötsch [5] reported a facile preparation of diethyl pyridazine-4,5-dicarboxylate in one step from commercially available pyridazine (Scheme 1, condition b), by radical bis-ethoxycarbonylation according to the Minisci procedure [6,7].

Scheme 1. Syntheses of 4,5-Dicyanopyridazine (1).

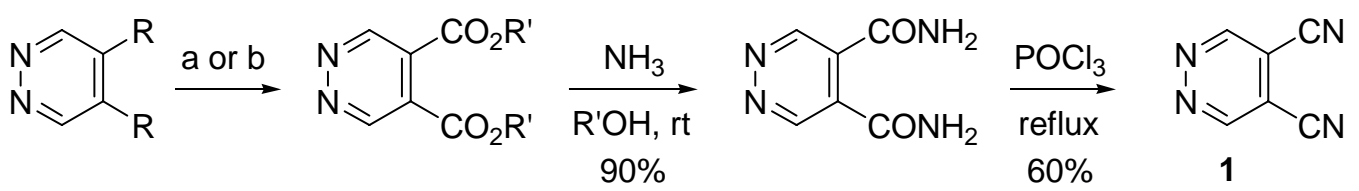

a: $\mathrm{R}=\mathrm{CO}_{2} \mathrm{H} ; \mathrm{HCl}(\mathrm{g})$, dry $\mathrm{MeOH}, \mathrm{rt}, 64 \%\left(\mathrm{R}^{\prime}=\mathrm{Me}\right)$

b: $\mathrm{R}=\mathrm{H} ; 30 \%$ aq $\mathrm{H}_{2} \mathrm{O}_{2}$, ethyl pyruvate, $-10^{\circ} \mathrm{C}-0^{\circ} \mathrm{C}, 15 \mathrm{~min}$, then added to pyridazine, $\mathrm{FeSO}_{4} \cdot 7 \mathrm{H}_{2} \mathrm{O}$, $\mathrm{H}_{2} \mathrm{SO}_{4}$ conc., $\mathrm{CH}_{2} \mathrm{Cl}_{2},-5^{\circ} \mathrm{C}-0^{\circ} \mathrm{C}, 76 \%$ (R' = Et)

\section{Hetero Diels-Alder (HDA) Reactions}

Aromatic pyridazine derivatives can participate as $4 \pi$-electron components in concerted cycloadditions [1-3]. In particular, $N$-oxides, $N$-imides, and $N$-ylides behave as 1 ,3-dipoles with different dipolarophiles and, starting from the pioneering works of Neunhoeffer [8-10] and Jojima 
[11], suitably substituted pyridazines have been exploited as azadienes in inverse electron-demand HDA reactions with electron-rich or strained dienophiles or in intramolecular processes [12-17]. In this context, while the great synthetic value of 1,2,4-triazines and 1,2,4,5-tetrazines as excellent azadienes in cycloaddition processes with a variety of dienophiles has been recognized over the past decades [12-23], little attention has been devoted to 1,2-diazines, probably due to some discouraging reports suggesting their inertness towards unactivated alkynes and alkenes [15,16]. On the other hand, against all expectations, 4,5-dicyanopyridazine exhibited a surprising behaviour as a heteroaromatic azadiene in inverse electron-demand HDA reactions with different dienophiles.

\subsection{Reactions of DCP with Dienes: A Direct Access to Carbo- and Hetero-Cage Systems}

On the basis of a long-term study concerning Diels-Alder (DA) reactions of nitrogen heterocycles, the strongly electron-deficient DCP, structurally resembling the highly dienophilic tetracyanoethylene, was first chosen to test the almost completely disregarded applications of aromatic pyridazines as $2 \pi$-electron components in [2+4] cycloadditions. In this context, the reaction of DCP (1) with

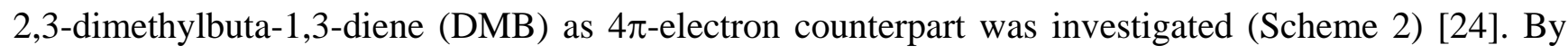
heating 1 with an excess of $\mathrm{DMB}$ in $\mathrm{CHCl}_{3}$ at $110{ }^{\circ} \mathrm{C}$, in a sealed tube, only minor amounts of compounds 3 and 4 resulting from the expected [2+4] process were isolated, while the main reaction product was the tricyclic cage compound 2 , obtained in $64 \%$ yield.

Scheme 2. Reaction of DCP with 2,3-dimethylbuta-1,3-diene.<smiles>N#Cc1cnncc1C#N</smiles>

1

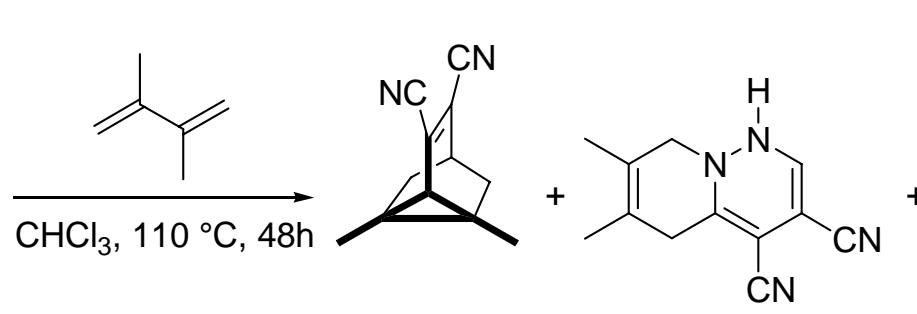

$264 \%$

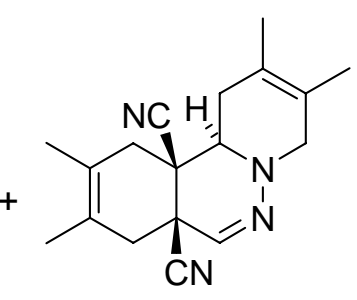

$48 \%$

The non-straightforward formation of $\mathbf{2}$ can be rationalized on the basis of a three-step pericyclic homodomino process [25] involving DCP as masked bis-diene [26]. A first inverse electron-demand [4+2] intermolecular HDA reaction of the electron-poor azadiene moiety of $\mathbf{1}$ on a double bond of $\mathrm{DMB}$, acting as dienophile, affords the primary cycloadduct 5 able to evolve via retro-DA with nitrogen extrusion into the vinyl substituted cyclohexadiene intermediate $\mathbf{6}$, then converted into the final product by an entropically assisted intramolecular Diels-Alder (IMDA) cycloaddition (Scheme 3).

Scheme 3. Mechanistic rationale for the formation of compound 2.

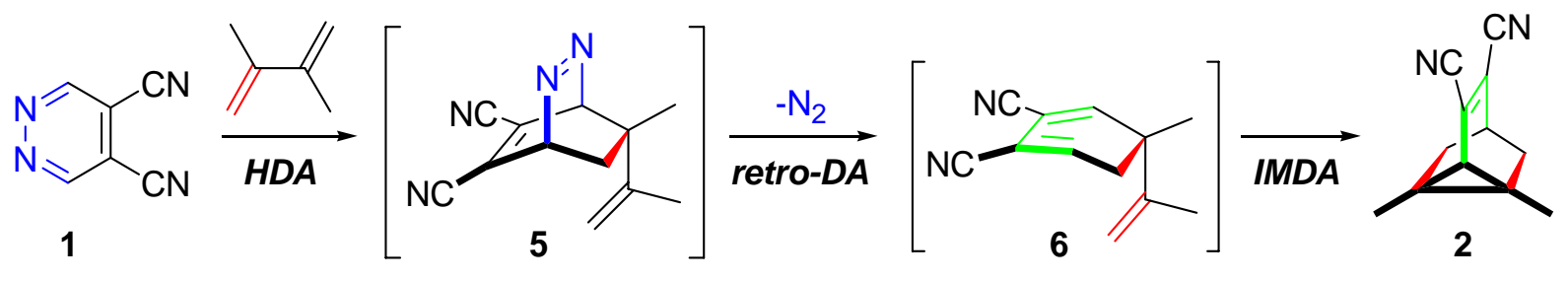


The above reaction was also performed with 4,5-dicyano-3,6-dimethylpyridazine [27]. Anyway, likely due to less favorable steric and electronic effects, the corresponding tetramethyl tricyclic derivative was isolated only operating at higher temperature and in low yield (26\%) [24].

Analogous domino processes of DCP with different bis-dienophiles have been exploited for direct access to polyfunctionalized carbo- and hetero-cage compounds, often isolated in high yields as sole reaction products (Table 1 , entries $1-8$ ) [28,29]. In particular, the almost quantitative formation of the tetracyclic cage system obtained by treatment with cycloocta-1,5-diene (COD, Table 1, entry 1) allowed evaluation of the higher reactivity of DCP as an azadiene in inverse electron-demand HDA reactions with respect to other electron-poor 1,2-diazines: in fact, a previous study concerning different pyridazine derivatives reported that only the highly activated tetramethyl pyridazine-3,4,5,6tetracarboxylate was able to react with COD, in more drastic conditions $\left(150{ }^{\circ} \mathrm{C}\right)$, affording the corresponding cage system in only $19 \%$ yield [17].

Figure 1. Molecular orbitals of tetramethyl pyridazine-3,4,5,6-tetracarboxylate and 4,5dicyanopyridazine.

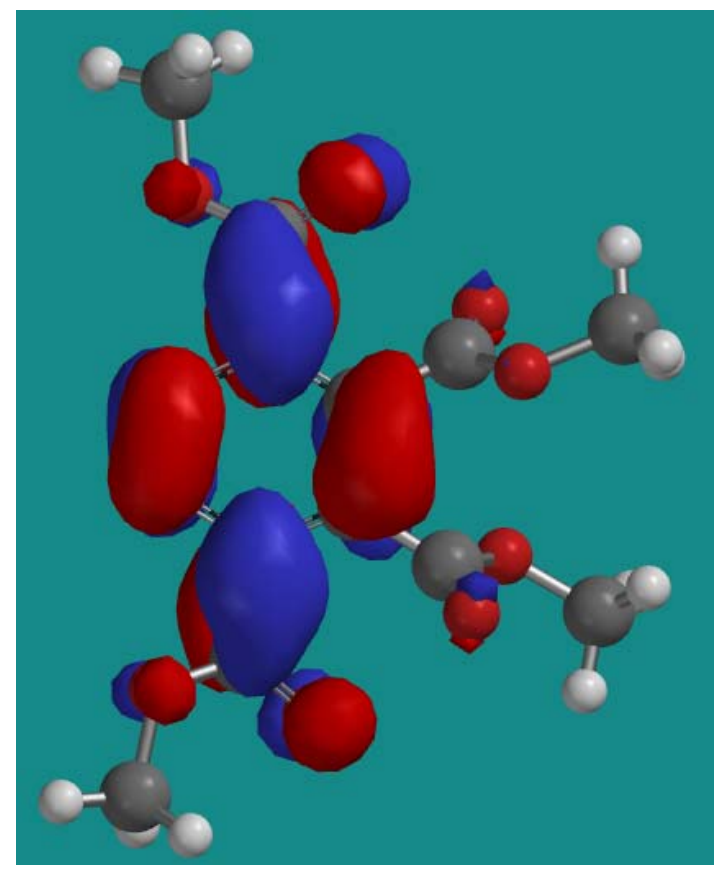

a) $\mathrm{LUMO} E=0.966 \mathrm{eV}$

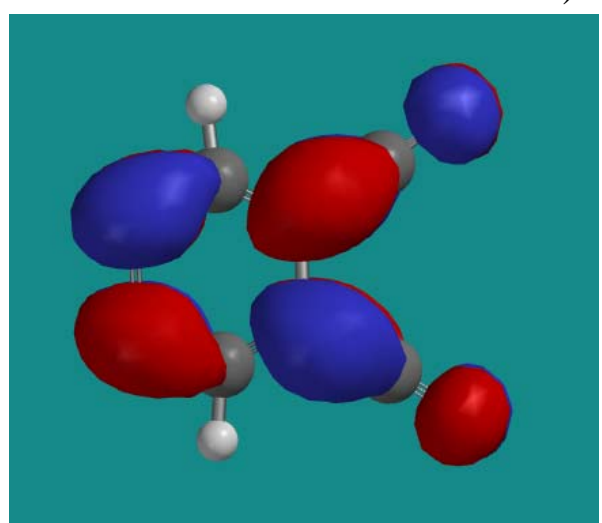

b) $\mathrm{LUMO} E=0.067 \mathrm{eV}$

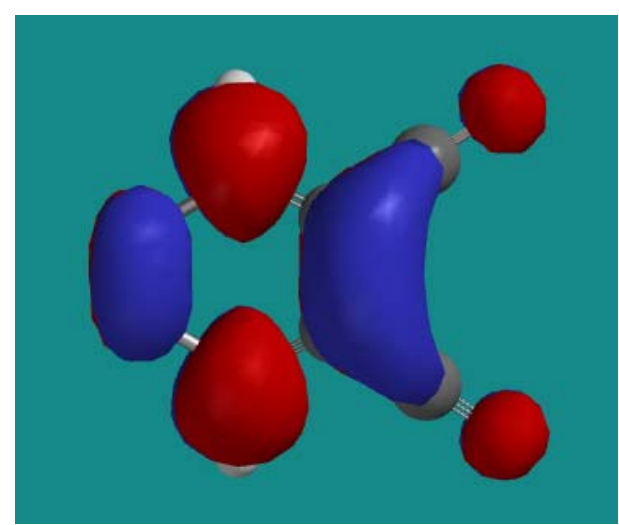

c) $\mathrm{LUMO}+1 E=1.636 \mathrm{eV}$ 
Although FMO calculations evidenced for DCP a LUMO of lower energy (0.067 eV, Figure 1b) with respect to the corresponding orbital of the tetraester $(0.966 \mathrm{eV}$, Figure 1a), this orbital can't participate to the HDA process due to unfavourable symmetry showing two nodes in the C-3 and C-6 positions. For this reason, DCP would be able to react with the LUMO+1 orbital, at higher energy (1.636 eV, Figure 1c) with respect to the tetraester LUMO (having a correct symmetry), and likely steric factors can be mainly invoked to justify the higher reactivity observed for the dinitrile.

A different reaction course was observed with cyclohexa-1,4-diene: a hydrogen transfer from the diene to DCP, followed by HCN elimination, is now preferred over the HDA process leading to 4-cyanopyridazine as the main reaction product (40\%) [28]. Higher functionalized bis-dienophiles gave the desired cage compounds after longer reaction times and in lower yields, likely due to unfavorable steric factors associated with competitive reactions of the cyclohexadiene intermediates (Table 1, entries 9-11). Moreover, reacting with allyl acrylate, a preferential aromatization of the cyclohexadiene derivative led exclusively to the corresponding phthalonitrile (Table 1, entry 12). On the other hand, a domino reaction of DCP and diallyldimethylsilane was unsuccessful and the cage system was synthesized through a two-step process involving formation of the cyclohexadiene intermediate under milder reaction conditions ( $70^{\circ} \mathrm{C}, 6$ days, 66\%) and subsequent IMDA reaction ( $110^{\circ} \mathrm{C}$, 9 days, 32\%), likely hampered by the encumbering methyl groups (Table 1, entry 13). Similar steric effects caused a significant decreasing of reactivity in the reaction with myrcene, characterized by a total sitoselectivity, and with the enantiopure terpenes $(R)-(-)-\beta$-citronellene and $(R)-(-)$-linalool affording the diastereomeric tricycloundecene systems (Table 1, entries 14-16). With longer bisdienophiles as octa-1,7-diene, nona-1,8-diene, and diallyl carbonate, the IMDA process was totally inhibited, probably due to unfavorable entropic effects and repulsive non-bonding interactions, and only cyclohexadiene derivatives were isolated (Table 1, entries 17-19).

Table 1. Reactions of DCP with dienes. ${ }^{\mathrm{a}}$

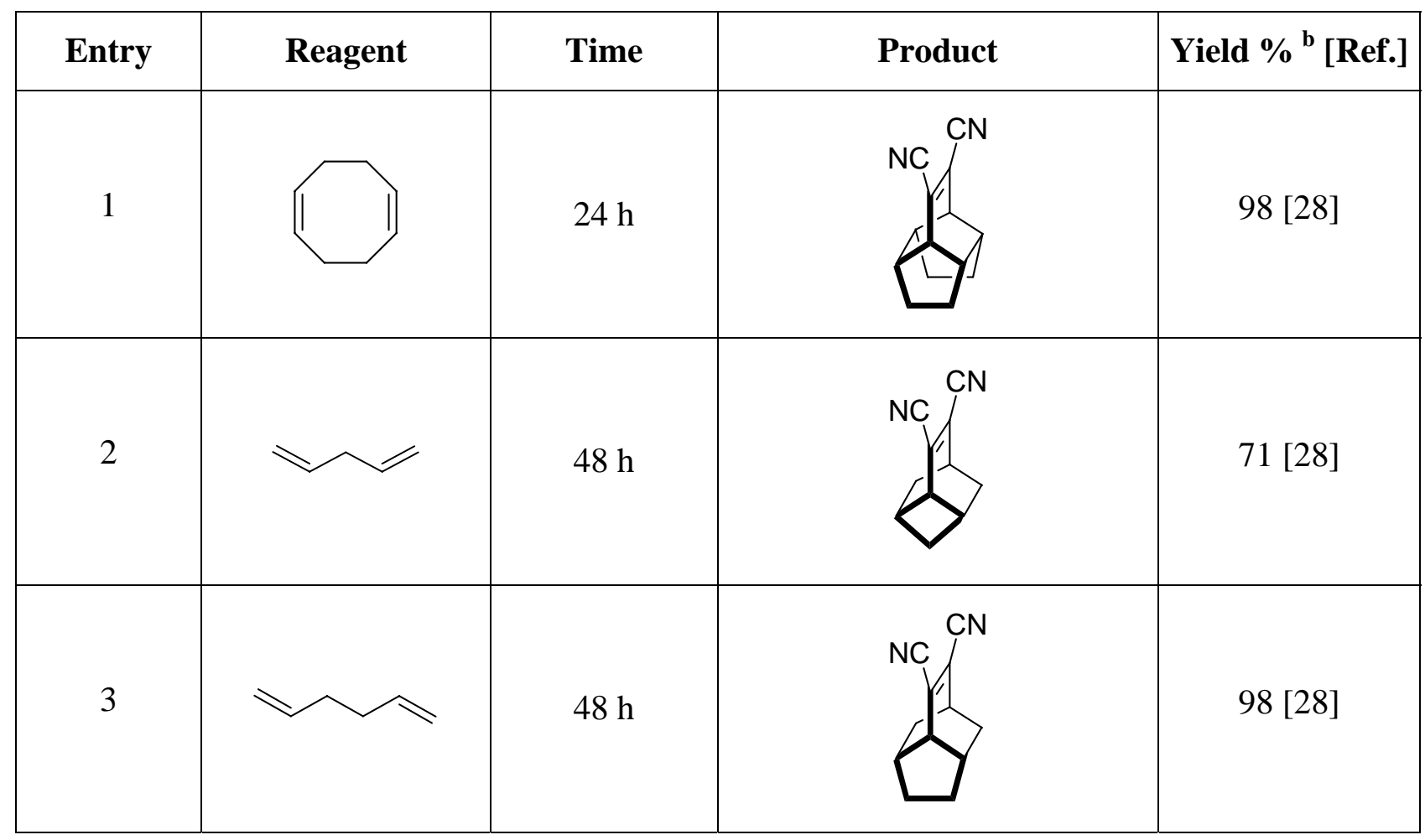


Table 1: Cont.

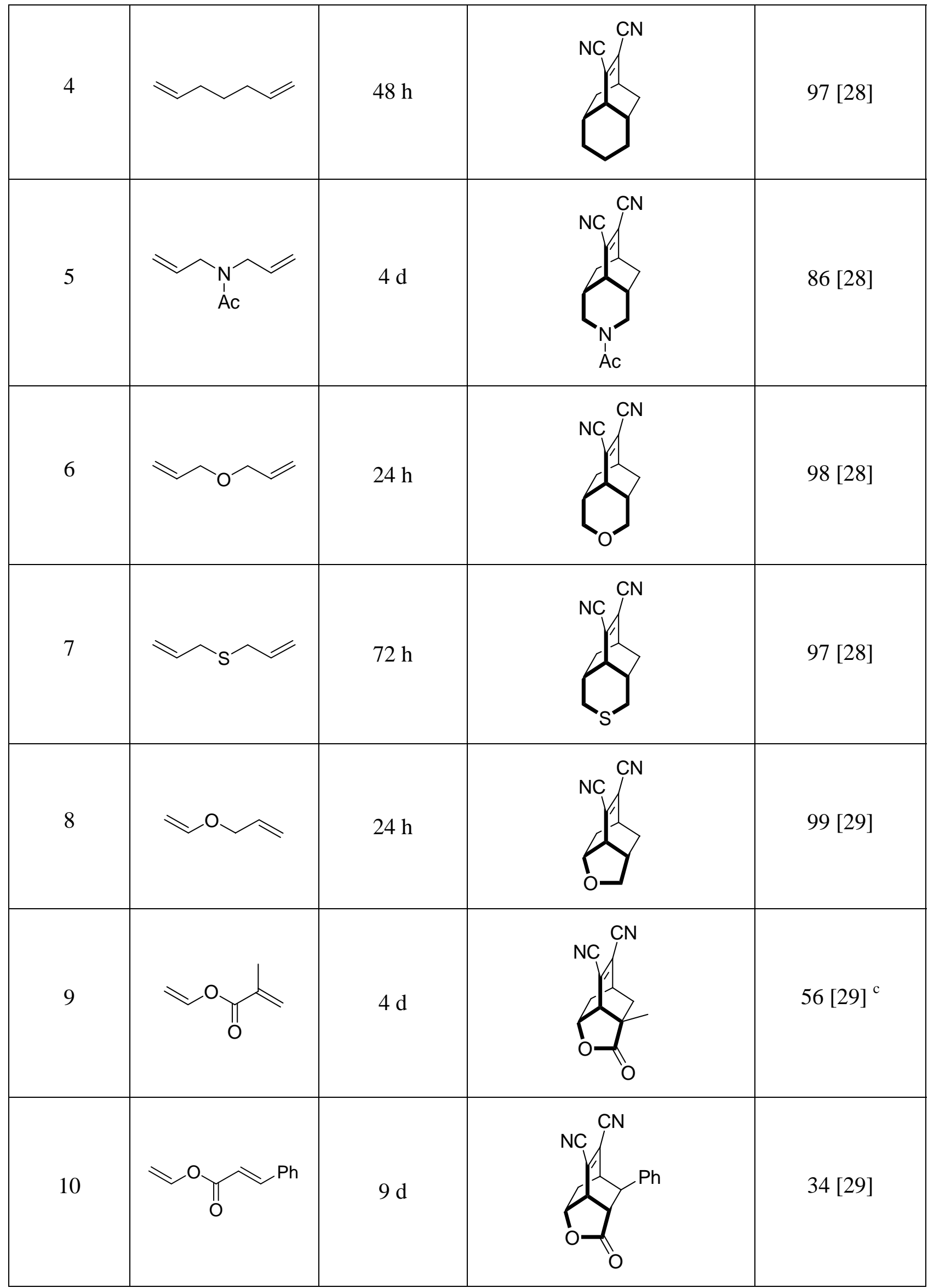


Table 1. Cont.

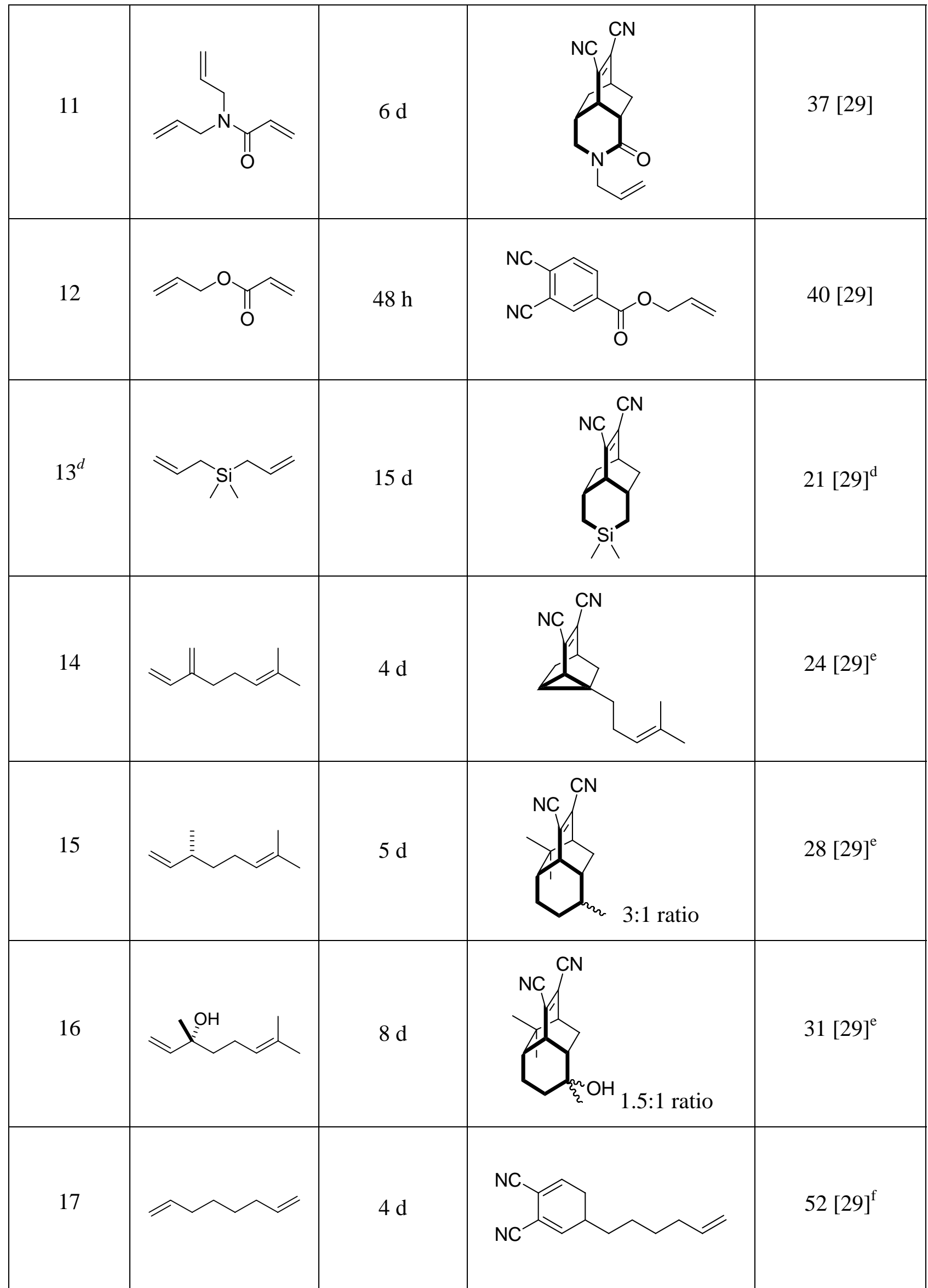


Table 1. Cont.

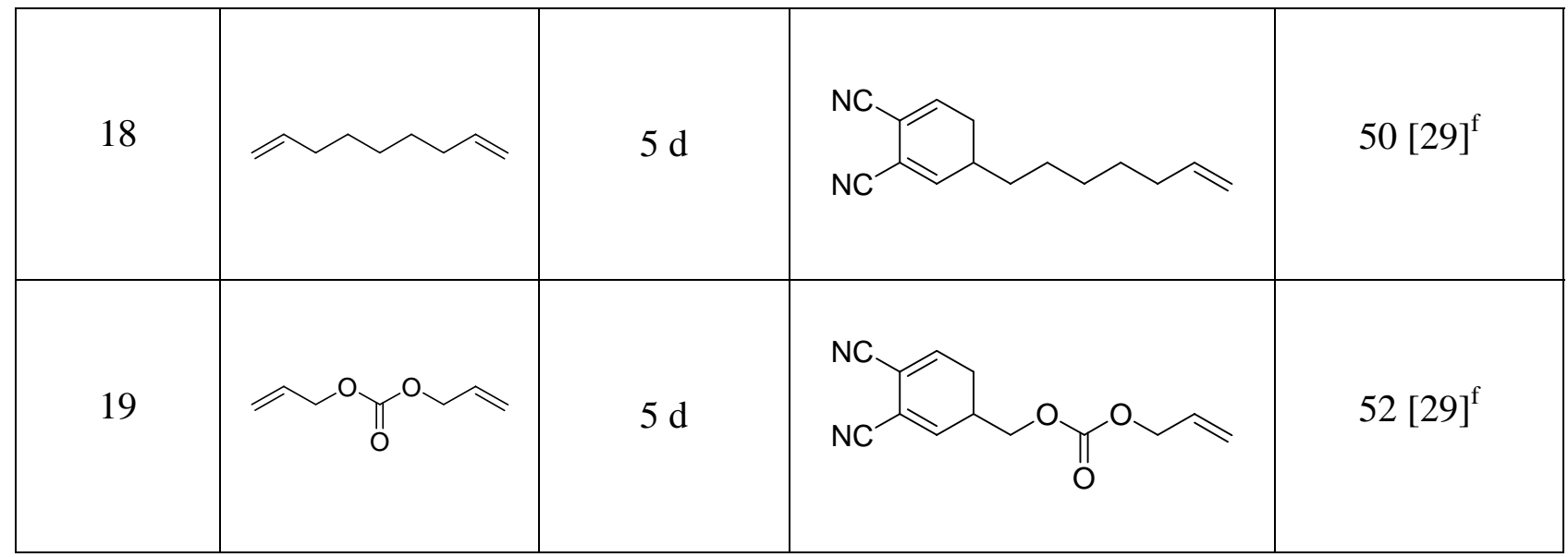

${ }^{\mathrm{a}}$ Reactions performed in a sealed tube in chloroform at $110^{\circ} \mathrm{C}$ with an excess (5 equiv) of reagent.

${ }^{\mathrm{b}}$ Isolated yields. ${ }^{\mathrm{c}}$ Phthalonitrile, formed by competitive elimination of methacrylic acid from the corresponding cyclohexadiene intermediate, was also recovered in $39 \%$ yield. ${ }^{\mathrm{d}}$ Reaction performed at $70^{\circ} \mathrm{C}$ for 6 days to isolate the cyclohexadiene intermediate then converted into the cage system by heating at $110{ }^{\circ} \mathrm{C}$ for 9 days. ${ }^{\mathrm{e}}$ Competitive aromatization of the corresponding cyclohexadiene intermediates afforded minor amounts of substituted phthalonitriles. ${ }^{\mathrm{f}}$ Reactions performed with 1.1 equiv. of reagent to reduce the formation of by-products.

\subsection{Reactions of DCP with Alkenes}

4,5-Dicyanopyridazine shows an exceptional reactivity towards different $2 \pi$-electron counterparts [30]. By treatment with an excess of the activated ethyl vinyl ether in chloroform at $50{ }^{\circ} \mathrm{C}$ : the intermediate 7, even under these mild conditions, escaped from isolation and it was converted into benzonitrile 8, by loss of EtOH, and mainly into the endo/syn and endo/anti adducts 9a,b and 10a,b, isolated as 1:1 and 4:1 regioisomeric mixtures in 65 and 15\% yields, respectively (Scheme 4) [31].

Scheme 4. HDA reaction of 1 with ethyl vinyl ether.

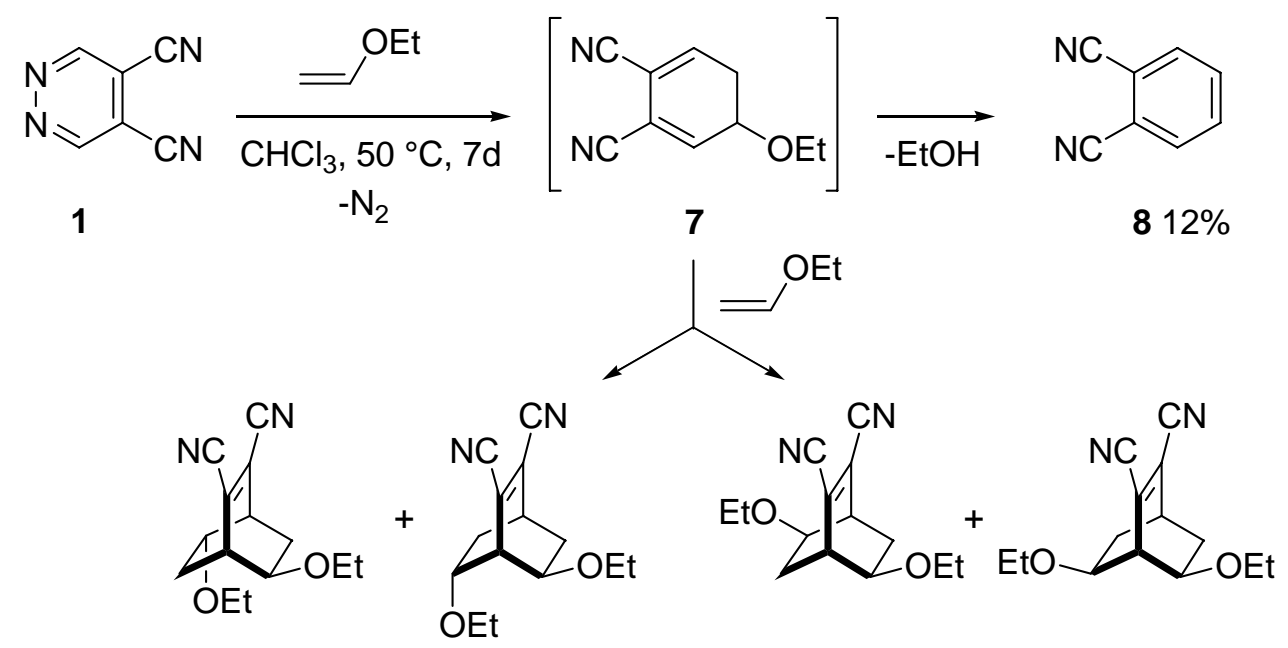

9a,b $1: 165 \%$

10a,b $4: 1 \quad 15 \%$ 
The reaction with the strained 1,2,3-triphenylcyclopropene in chloroform at $110{ }^{\circ} \mathrm{C}$ afforded the cycloheptatriene 12 in 77\% yield through a [4+2] HDA cycloaddition followed by ring-enlargement via electrocyclic ring-opening of the cyclohexadiene moiety (Scheme 5). Nevertheless, DCP prefers to react as nucleophile with the strongly electrophilic diphenylcyclopropenone leading to bicyclic pyridazine derivatives 13 and 14 [31]. HDA reactions with different cycloalkenes allowed to prepare bicyclic dicyanocyclohexadienes 15a-c (Scheme 5). With cyclopentene and cyclohexene, the yields of compounds 15a,b were lowered due to the competing formation of bis-adducts and aromatization products [31].

Scheme 5. Reactions of 1 with cycloalkenes.<smiles>N#Cc1cnncc1C#N</smiles>

1

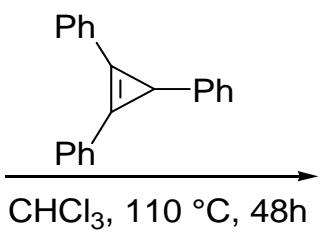

$-\mathrm{N}_{2}$<smiles>N#CC1=CC(c2ccccc2)C(c2ccccc2)=C(C#N)C(c2ccccc2)C1c1ccccc1</smiles>

11
$1277 \% \mathrm{Ph}$

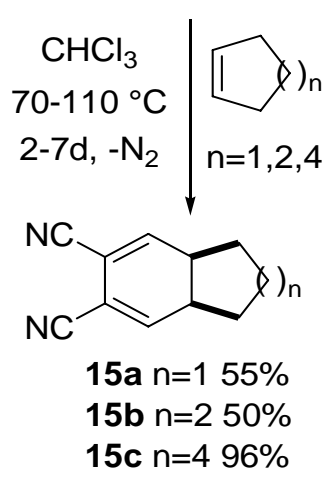

$\mathrm{CHCl}_{3}$

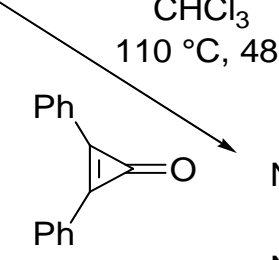<smiles>N#Cc1cn2c(-c3ccccc3)c(-c3ccccc3)c(=O)n2cc1C#N</smiles>

$1338 \%$<smiles>N#Cc1cnn2c(-c3ccccc3)c(-c3ccccc3)c(OC(=O)/C(=C/c3ccccc3)c3ccccc3)c2c1C#N</smiles>

$1447 \%$

Treatment of DCP with an excess of styrene at $110{ }^{\circ} \mathrm{C}$ in the presence of $10 \% \mathrm{Pd} / \mathrm{C}$, to favor the aromatization of the cyclohexadiene intermediate 16, allowed to isolate 3,4-dicyanobiphenyl 17 in $38 \%$ yield. Compound 16 was the predominant product operating at $70{ }^{\circ} \mathrm{C}$ with a stoichiometric amount of reagent but it escaped any efforts of isolation [31]. The dinitrile $\mathbf{1}$ was also able to react at $110^{\circ} \mathrm{C}$ with electron-poor alkenes, as methyl acrylate and methyl methacrylate, leading to the aromatic ester 19 and the diene 18b in 58 and 64\% yields, respectively (Scheme 6) [31].

Scheme 6. HDA reactions of $\mathbf{1}$ with linear alkenes.<smiles>N#Cc1cnncc1C#N</smiles>

1<smiles>[R]C(=C)CCC(=O)OC</smiles>

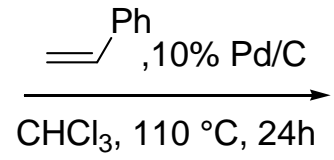

$-\mathrm{N}_{2}$<smiles>N#CC1=CCC(c2ccccc2)C=C1C#N</smiles>

16<smiles>N#Cc1ccc(-c2ccccc2)cc1C#N</smiles>

$1738 \%$<smiles>[R][C@H](C)C1(F)C=C(C#N)C(C#N)=CC1</smiles>

$18 \mathrm{a} \mathrm{R}=\mathrm{H}$

$1958 \%$

$$
\text { 18b } R=\text { Me 64\% }
$$




\subsection{Reactions of DCP with Alkynes and Enamines}

Phthalonitriles, key building blocks for the synthesis of phthalocyanines whose importance is associated to manifold applications in different fields of material science (see Section 5), are generally obtained by multistage elaboration of aromatic precursors. On the other hand, a novel complementary direct approach to variously substituted phthalonitriles was achieved through HDA cycloadditions of DCP with alkynes and enamines (Table 2). [32]. The aromatic products 22, isolated in satisfactory yields, come from the primary adducts $\mathbf{2 0}$ and $\mathbf{2 1}$ by nitrogen extrusion or sequential elimination of nitrogen and amine, respectively (Scheme 7).

Scheme 7. HDA reactions of 1 with alkynes and enamines.

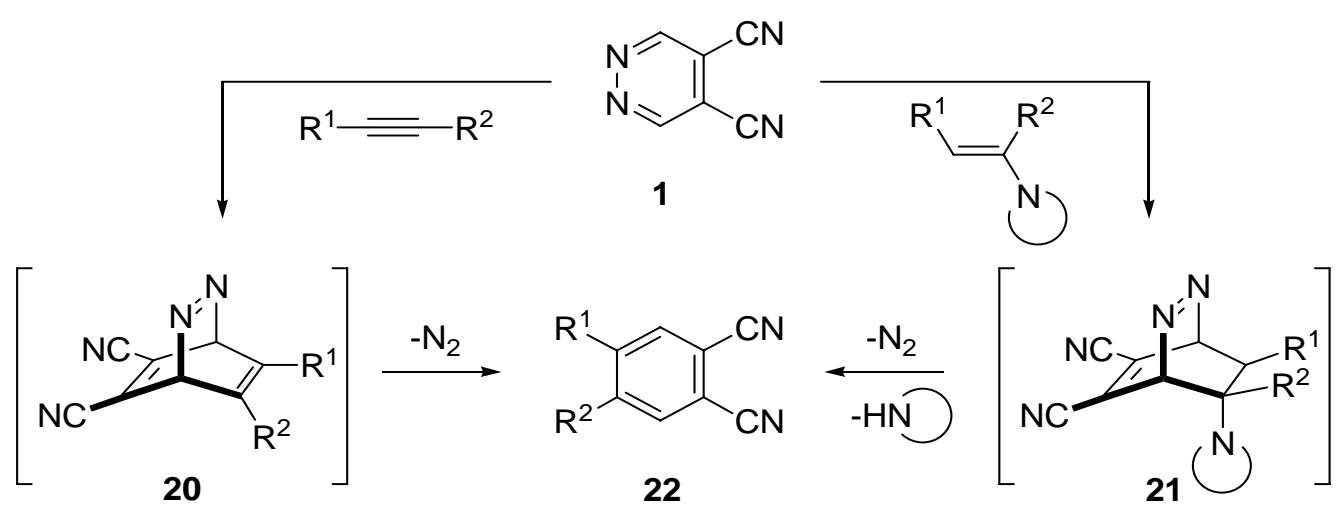

While DCP was able to react at room temperature with the electron-rich ynamine affording the corresponding phthalonitrile derivative in $85 \%$ yield, silylacetylenes required more drastic conditions $\left(110^{\circ} \mathrm{C}\right.$ ) but allowed the isolation of the reaction products in almost quantitative yields (Table 2, entries 1-3). Reactions of scarcely activated or hindered alkynes were performed at $150{ }^{\circ} \mathrm{C}$ in xylene, for longer reaction times, leading to substituted phthalonitriles in lower yields (42-72\%) (Table 2, entries 4a, 5a, 6, 7a, 8a). With the exception of highly hindered and/or less activated enamines that showed poor dienophilic properties towards 1 (Table 2, entries $5 \mathrm{~b}$ and 8b), replacement of alkynes with the corresponding enamines allowed to achieve satisfactory yields (Table 2, entries 4b and 7b). Good results were obtained with cyclic enamines, affording condensed phthalonitriles (Table 2, entries 9a, 10a, 11a) [32]. When the reactions of DCP with cyclic enamines and (E)-4-(pent-2-en-3yl)morpholine were performed in dichloromethane at room temperature for 24 hours, morpholinodicyano-cyclohexadiene derivatives 24 were obtained in high yields through a [1,5] sigmatropic rearrangement of intermediates 23 (Scheme 8). Operating with 4-(1-cyclopenten-1-yl) morpholine, it was possible to characterize the corresponding intermediate 23 via ${ }^{1} \mathrm{H}$ and ${ }^{13} \mathrm{C}$ NMR analyses. 
Table 2. Synthesis of phthalonitriles from reactions of DCP with alkynes and enamines. ${ }^{\text {a }}$

\begin{tabular}{|c|c|c|c|c|}
\hline Entry & Reagent & Conditions & Product & Yield \% ${ }^{b}$ [Ref.] \\
\hline 1 & $=\mathrm{NEt}_{2}$ & $\mathrm{CH}_{2} \mathrm{Cl}_{2}, 25^{\circ} \mathrm{C}, 19 \mathrm{~h}$ & & 85 [32] \\
\hline 2 & $\mathrm{Me}_{3} \mathrm{Si}=\mathrm{SiMe}_{3}$ & $\mathrm{CHCl}_{3}, 110^{\circ} \mathrm{C}, 48 \mathrm{~h}$ & & 98 [32] \\
\hline 3 & $\mathrm{Me}_{3} \mathrm{Si}=$ & $\mathrm{CHCl}_{3}, 110^{\circ} \mathrm{C}, 8 \mathrm{~d}$ & & 98 [32] \\
\hline $4 a$ & $\mathrm{Ph}=$ & xylene, $150^{\circ} \mathrm{C}, 24 \mathrm{~h}$ & & 42 [32] \\
\hline $4 b$ & & $\mathrm{CHCl}_{3}, 70{ }^{\circ} \mathrm{C}, 24 \mathrm{~h}$ & & 72 [32] \\
\hline $5 a$ & $\mathrm{EtO}_{2} \mathrm{C}-$ & xylene, $150^{\circ} \mathrm{C}, 5 \mathrm{~d}$ & & 55 [32] \\
\hline $5 b$ & & $\mathrm{CHCl}_{3}, 70^{\circ} \mathrm{C}, 24 \mathrm{~h}$ & & 29 [32] \\
\hline 6 & $\mathrm{Et}=\mathrm{Et}$ & xylene, $150{ }^{\circ} \mathrm{C}, 10 \mathrm{~d}$ & & 55 [32] \\
\hline
\end{tabular}


Table 2. Cont.

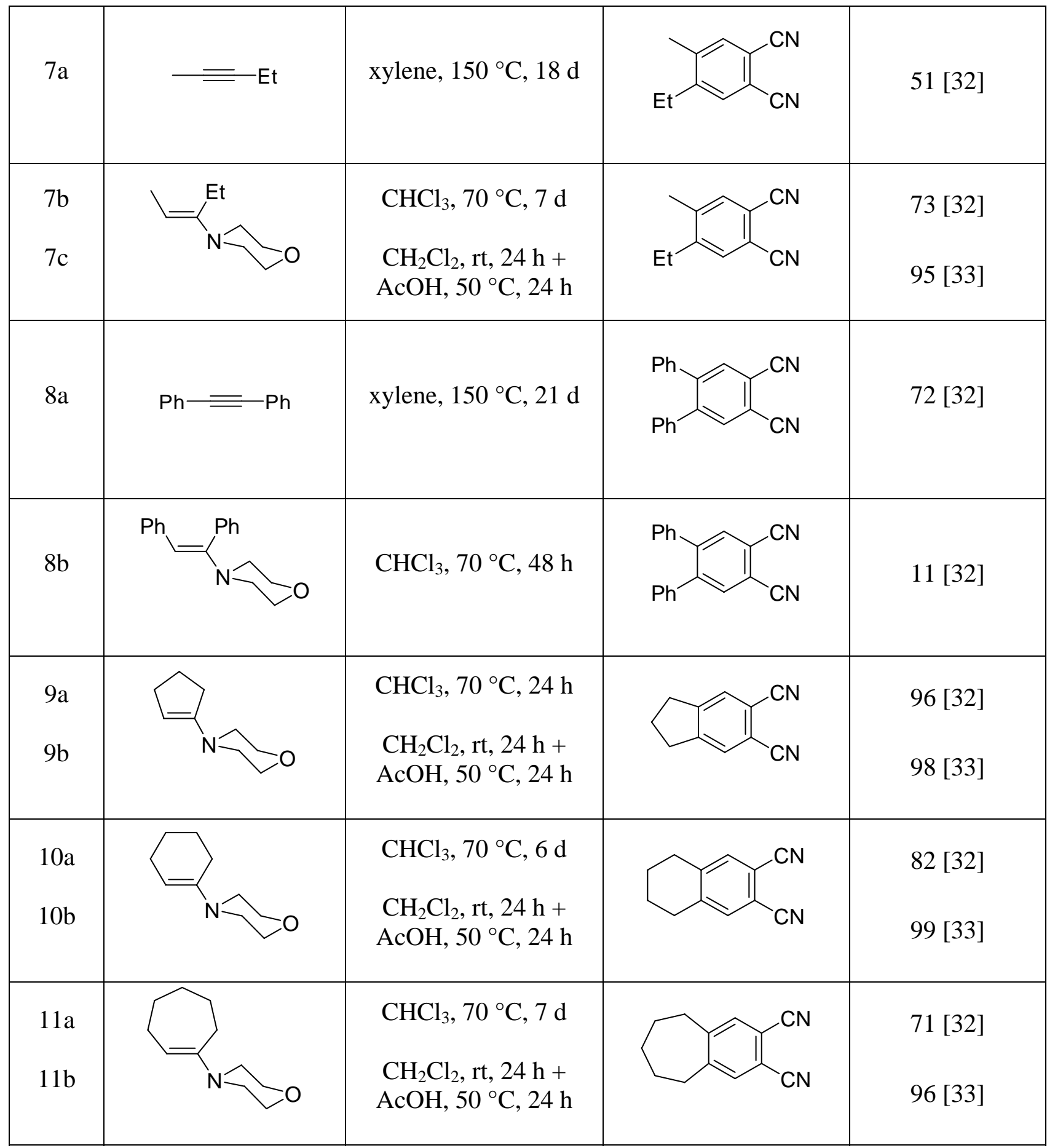

${ }^{\mathrm{a}}$ Reactions performed in a sealed tube with an excess of reagent (1.1-10 equiv). ${ }^{\mathrm{b}}$ Isolated yields.

This observation allowed an improved one-pot synthesis of the corresponding phthalonitriles 22: in fact, by operating first at room temperature in dichloromethane for 24 hours and then, once formed compounds 24 , by addition of acetic acid and heating at $50{ }^{\circ} \mathrm{C}$ for the same time, to favor the amine elimination step, the desired products were isolated in almost quantitative yields (Table 2, entries 7c, 9b, 10b, 11b) [33]. 
Scheme 8. Mechanistic study of reactions of $\mathbf{1}$ with enamines.<smiles>[R]C=C([R])N[R]</smiles>

1

1. $\mathrm{CH}_{2} \mathrm{Cl}_{2}$, rt, $24 \mathrm{~h}$

2. $\mathrm{CH}_{3} \mathrm{CO}_{2} \mathrm{H}$, $50{ }^{\circ} \mathrm{C}, 24 \mathrm{~h}$

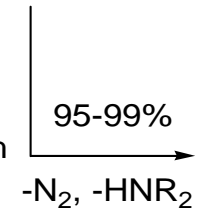

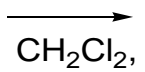
rt, $24 \mathrm{~h}$<smiles>C1CCNC1</smiles>

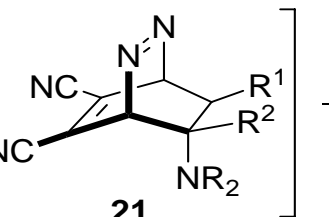

21<smiles>[R]C1C=C(C#N)C(C#N)=CC1([R2])[R16]</smiles>

$[1,5]$

23

$\mathrm{R}^{1}-\mathrm{R}^{2}=\left(\mathrm{CH}_{2}\right)_{3}$ $\mathrm{R}^{1}-\mathrm{R}^{2}=\left(\mathrm{CH}_{2}\right)_{4}$ $\mathrm{R}^{1}-\mathrm{R}^{2}=\left(\mathrm{CH}_{2}\right)_{5}$ $\mathrm{R}^{1}=\mathrm{Me}, \mathrm{R}^{2}=\mathrm{Et}$ $\mathrm{NR}_{2}=-\mathrm{\xi}^{\mathrm{N}} \widehat{\mathrm{N}}$

\subsection{Reactions of DCP with Heterocyclic Dienophiles}

Although indole and carbazole derivatives, intensively studied for their pharmacological properties, are mainly synthesized through cyclization of suitably substituted aromatic carbocycles, alternative routes based on cycloaddition processes have also been reported [34-38]. In particular, in the last fifteen years electron-rich heterocycles with latent enamine functionalities, such as pyrrole and indole derivatives, have been widely exploited as $2 \pi$-electron components in inter- and intramolecular inverse electron-demand HDA reactions, mainly with 1,2,4,5-tetrazines and 1,2,4-triazines [16,20,21] for a facile access to complex indole alkaloids. Although in this context, apart from a few exceptions, 1,2diazines played a minor role, reactions of dinitrile 1 with pyrrole and indole dienophiles were studied. HDA reactions of DCP with $N$-methylpyrrole in xylene at $150^{\circ} \mathrm{C}$ afforded dicyanoindole 27 in only 17\% yield, by spontaneous aromatization of intermediate 26, coming from the primary adduct 25. Attempts to improve this result by changing the reaction conditions were unsuccessful and operating in the presence of catalyst, as $\mathrm{CuI}$ or $10 \% \mathrm{Pd} / \mathrm{C}$ to favor the final aromatization step, compounds $\mathbf{2 8}$ and 29, coming from competitive $S_{N} A r 2$ reactions of the pyrrole derivative on the strongly electrophilic C-4 carbon of DCP (see Section 4), were obtained as main reaction products (Scheme 9) [39].

Scheme 9. HDA reactions of DCP with $N$-methylpyrrole.

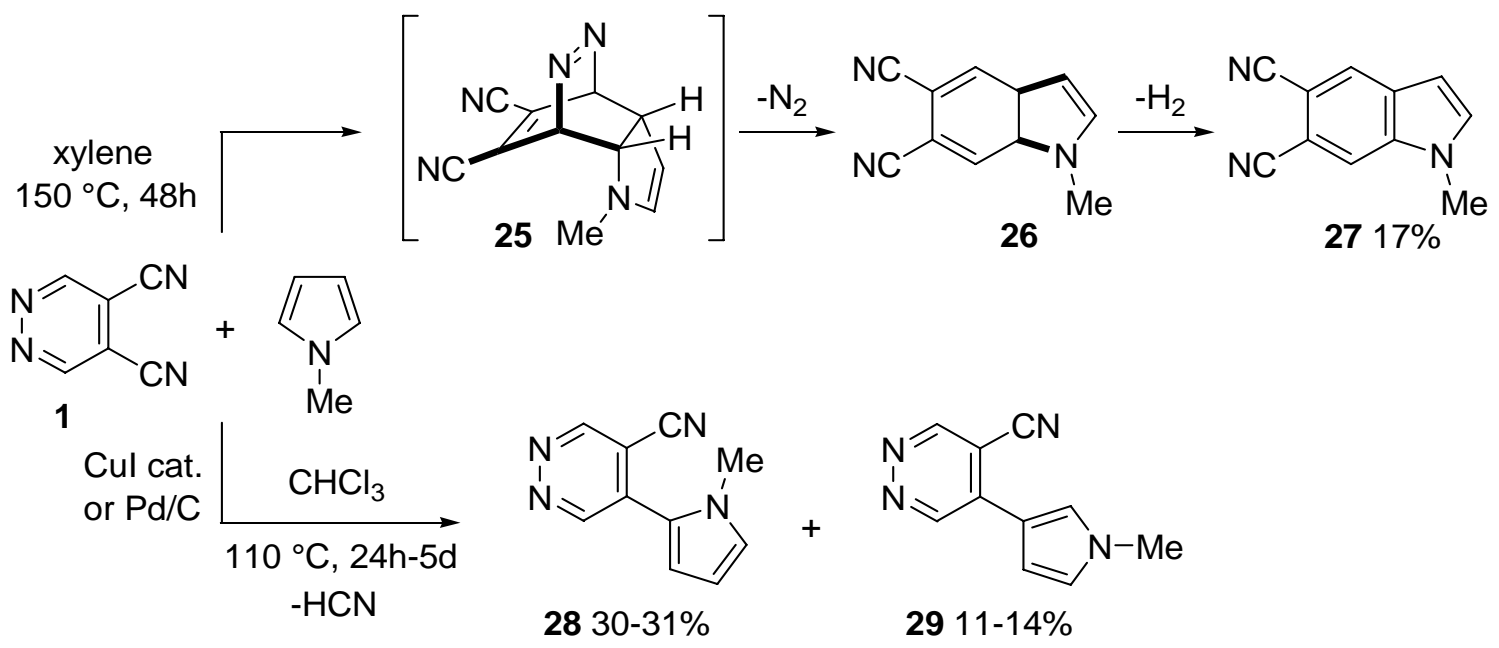


Better results were achieved with the more dienophilic indole and $N$-methylindole, leading to the carbazole derivatives 30a,b in 57 and 62\% yields, respectively. Anyway, in both cases, minor amounts of substitution products 31a,b were obtained. Moreover, while 3-acetoxy and 3-ethylthioindole were completely inert towards DCP, 2-ethylthioindole easily reacted with $\mathbf{1}$ but only compound 31c was isolated in 92\% yield (Scheme 10) [39].

Scheme 10. HDA reactions of DCP with indole derivatives.<smiles>[R]c1cc2ccccc2n1[R]</smiles>

1

a: $\mathrm{R}^{1}=\mathrm{R}^{2}=\mathrm{H}$, xylene, $150{ }^{\circ} \mathrm{C}, 72 \mathrm{~h}, 30 \mathrm{a} 57 \%$ and $31 \mathrm{a} 9 \%$

b: $\mathrm{R}^{1}=\mathrm{Me}, \mathrm{R}^{2}=\mathrm{H}, \mathrm{CHCl}_{3}, 110^{\circ} \mathrm{C}, 80 \mathrm{~h}, 30 \mathrm{~b} 62 \%$ and $31 \mathrm{~b} 14 \%$

c: $\mathrm{R}^{1}=\mathrm{H}, \mathrm{R}^{2}=\mathrm{SEt}, \mathrm{CHCl}_{3}, 110{ }^{\circ} \mathrm{C}, 60 \mathrm{~h}, 31 \mathrm{c} 92 \%$<smiles>[R16][Y]n1c2ccccc2c2cc(C#N)c(C#N)cc21</smiles><smiles>[R]c1c(-c2cnncc2C#N)c2ccccc2n1[R]</smiles>

31a,b,c

The synthesis of indole derivatives was improved by using the non-aromatic 2-methylthiopyrroline as a strongly activated dienophile (Scheme 11).

Scheme 11. HDA reactions of DCP with 2-methylthiopyrroline.

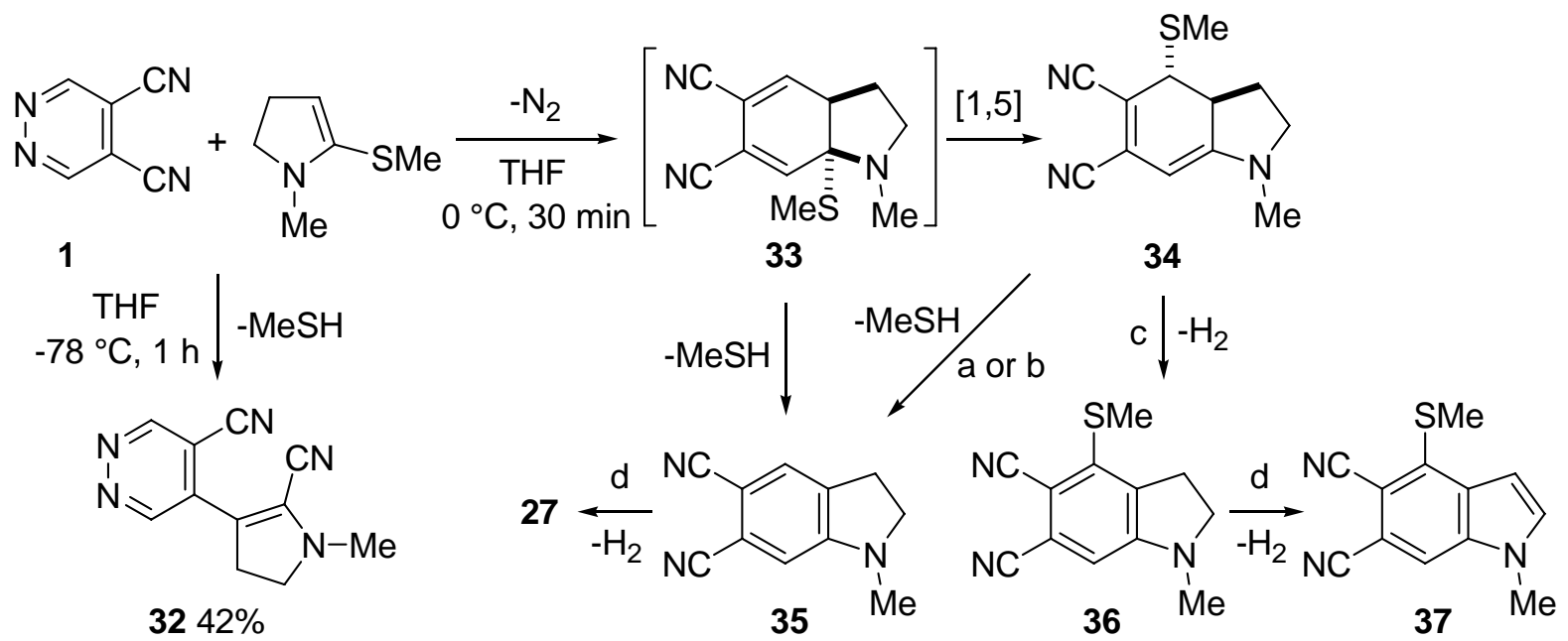

a: EtOAc, $110{ }^{\circ} \mathrm{C}, 24$ h, 98\%; b: $t$-BuOK, THF, rt, 24 h, 97\%; c: DDQ, PhH, rt, 24 h, 60\%;

d: DDQ, $\mathrm{PhH}, 80{ }^{\circ} \mathrm{C}, 12 \mathrm{~h}, 97 \%$

Although at low temperature $\left(-78{ }^{\circ} \mathrm{C}\right)$ the substitution pathway leading to compound 32 as predominant product is strongly preferred, by operating at $0{ }^{\circ} \mathrm{C}$ in THF for 30 minutes the bicyclic systems 34 and 35 were isolated in 50 and 23\% yields, respectively [40]. The formation of $\mathbf{3 4}$ and 35 can be rationalized through two domino processes involving a [4+2] HDA reaction of 1 with loss of nitrogen affording the intermediate $\mathbf{3 3}$ and, respectively, a [1,5] sigmatropic rearrangement, as 
previously observed with enamines [33], or methanethiol elimination. Moreover, compound 34 is able to evolve into 35 and 36 by elimination of $\mathrm{MeSH}$ or $\mathrm{H}_{2}$. Then, this alternative methodology, now involving multi-step processes, allows to synthesize $\mathbf{2 7}$ in $70 \%$ overall yield, as well as the thiomethyl derivative 37, through aromatization of $\mathbf{3 5}$ and 36, respectively.

On the other hand, HDA reactions with heterocyclic enol ethers as dienophiles resulted in the formation of bis-adducts, as previously observed with ethyl vinyl ether (see Section 3.2). In fact, 2,3-dihydrofuran afforded the tetracyclic derivatives 39a,b, as a 3:1 regioisomeric mixture, through endo/anti cycloaddition of the excess of dienophile on the cyclohexadiene intermediate $38(\mathrm{n}=0)$, together with minor amounts of 40a,b (1.5:1 mixture) arising from endo/syn or exo/anti approaches. The phthalonitrile $\mathbf{4 1}$ was the main product from the reaction of DCP and 3,4-dihydro-2H-pyran, obtained by ring-opening of the corresponding intermediate $38(n=1)$ and trapping with the excess of reagent (Scheme 12) [40].

Scheme 12. HDA reactions of DCP with dihydroheterocycles.<smiles>N#Cc1cnncc1C#N</smiles>

1

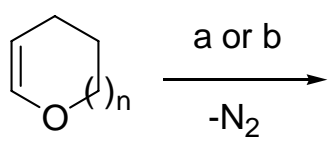

$n=0,1$<smiles>N#CC1=CC2CCC(=O)OC2C=C1C#N</smiles>

38<smiles>O=PC1CCCO1</smiles><smiles>C1=COCCC1</smiles>

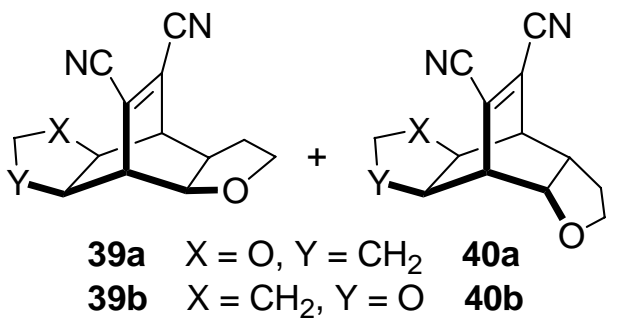<smiles>N#Cc1ccc(CCC[OH+])cc1C#N</smiles>

$4168 \%$

$(3: 1) 88 \%$

$(1.5: 1) 6 \%$

a: $\mathrm{n}=0, \mathrm{CHCl}_{3}, 70^{\circ} \mathrm{C}, 72 \mathrm{~h} ; \mathrm{b}: \mathrm{n}=1$, toluene, $110^{\circ} \mathrm{C}, 7 \mathrm{~d}$

\section{Nucleophilic Aromatic Substitutions on DCP}

The nucleophilic substitution of the cyano group in cyano heterocycles is quite unusual and only a few examples have been reported concerning 1,2,4-triazinecarbonitriles [41,42], quinazoline-[42] and quinazolinone-carbonitriles [43], pyrazine-2,3-dicarbonitriles [44], and pyridine-[45] and pyridiniumcarbonitriles [46]. In the pyridazine series, the formal replacement of the CN group has been observed in the treatment of 4-cyano-3(2H)-pyridazinone or tetrazolo[1,5- $b$ ]pyridazine-8-carbonitrile with phenylmagnesium chloride [47], as well as in the reactions of 1-phthalazine- and 4-cinnolinecarbonitrile with Grignard reagents [48] and cinnoline-3,4-dicarbonitrile with amines [49]. Moreover, as reported in Schemes 9 and 10, the study of HDA reactions of DCP with pyrrole and indole systems allowed to isolate the corresponding substitution products 28, 29, and 31 [39]. On this ground, and with the aim to elucidate the behavior of the dinitrile $\mathbf{1}$ as heterocyclic electrophile in nucleophilic aromatic substitution, the above reactions were repeated in different experimental conditions. In particular, operating at room temperature (or at $50{ }^{\circ} \mathrm{C}$ ) in glacial acetic acid as solvent, without any 
catalysts, indole and $N$-methylindole led to indolylpyridazines 31a,b in 91 and 99\% yields, respectively, while $N$-methylpyrrole gave the regioisomeric pyrrolylpyridazines 28 and 29 in 68 and $13 \%$ yields and the more reactive pyrrole afforded, after only 4 days at room temperature, derivative 42 in 91\% yield, together with minor amount of dihydropyridazine 43 (8\%) (Scheme 13) [50].

Scheme 13. $\mathrm{S}_{\mathrm{N}} \mathrm{Ar} 2$ reactions of DCP with pyrrole and indole nucleophiles.<smiles>[R]n1cc(-c2cnncc2C#N)c2ccccc21</smiles>

$31 \mathrm{a} R=\mathrm{H} \quad 91 \%$

31b $\mathrm{R}=$ Me $99 \%$

a: $\mathrm{R}=\mathrm{H}, \mathrm{AcOH}, \mathrm{rt}, 9 \mathrm{~d}$

b: $\mathrm{R}=\mathrm{Me}, \mathrm{AcOH}, \mathrm{rt}, 18 \mathrm{~d}$ or $50^{\circ} \mathrm{C}, 22 \mathrm{~h}$

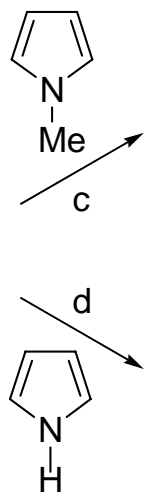<smiles>Cn1ccc(-c2cnncc2C#N)c1</smiles>

$2868 \%$

$2913 \%$<smiles>CC1(c2ccc[nH]2)C=NNC=C1C#N</smiles>

42 91\%

$438 \%$

c: $\mathrm{AcOH}, \mathrm{rt}, 15 \mathrm{~d}$; d: $\mathrm{AcOH}, \mathrm{rt}, 4 \mathrm{~d}$

These results clearly show the importance of the acidity in the substitution pathway, likely involving the LUMO of protonated DCP at lower energy $(-5.883 \mathrm{eV})$ with respect to the corresponding orbital of $1(0.067 \mathrm{eV})$. Moreover, the acidic medium, through protonation of the pyridazine nitrogen, seems to play a crucial role in the HDA/ $S_{N} A r 2$ competition, in favor of the latter process.

Scheme 14. Two-step mechanism involving nucleophilic addition and elimination reactions.

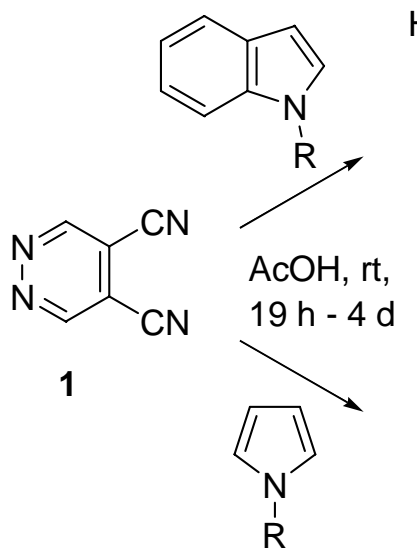

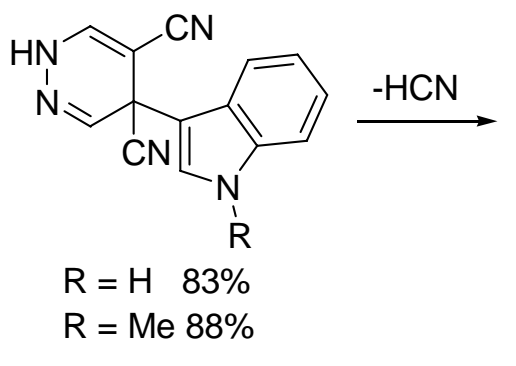<smiles>[R]n1cc(-c2cnncc2C#N)c2ccccc21</smiles>

$31 a, b$

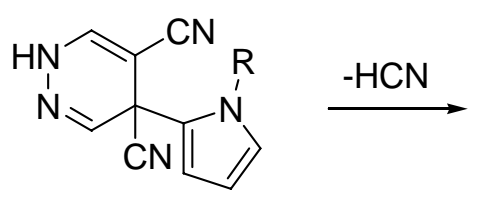

$\mathrm{R}=\mathrm{H} \quad 72 \%$

$\mathrm{R}=\mathrm{Me} 52 \%$<smiles>[R]n1cccc1-c1cnncc1C#N</smiles>

28,42

The isolation of the 1,4-adduct 43, from reaction with pyrrole, led to a mechanistic investigation of the substitution processes. Then, performing the above reactions in the same conditions but for shorter reaction times, dihydropyridazine derivatives were isolated in 52-88\% yields. These intermediates were easily converted into the final products by simple stirring in $\mathrm{AcOH}$ at room temperature, through spontaneous HCN elimination. These data clearly show that the nucleophilic substitution products are actually the fruit of a two-step process, involving nucleophilic addition and elimination reactions 
(Scheme 14). To assess applications and limits of this new reactivity of DCP, reactions with different pyrrole and indole nucleophiles in acetic acid were studied.

Scheme 15. $S_{N} A r 2$ reactions of DCP with substituted pyrrole and indole nucleophiles.<smiles>Cc1[nH]c2ccccc2c1-c1cnncc1C#N</smiles>

$4494 \%$<smiles>N#Cc1cnncc1-c1c(-c2ccccc2)[nH]c2ccccc12</smiles>

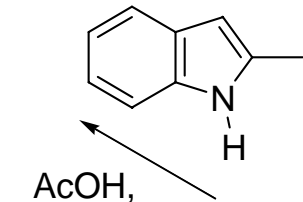

$50{ }^{\circ} \mathrm{C}, 24 \mathrm{~h}$

$\mathrm{AcOH}$, $70{ }^{\circ} \mathrm{C}, 72 \mathrm{~h}$<smiles>c1ccc(-n2cccc2)cc1</smiles><smiles>C[14C]1CC1</smiles>
$110{ }^{\circ} \mathrm{C}, 4 \mathrm{~d}$<smiles>N#Cc1cnncc1C#N</smiles>

1

$\mathrm{AcOH}$<smiles>N#Cc1cnncc1-c1cccn1-c1ccccc1</smiles>

$4623 \%$<smiles>Cn1cccc1COc1cccn1C</smiles>

$4778 \%$

While DCP was absolutely inert towards electron-deficient-pyrrole and indole derivatives, 2-methylindole gave compound 44 in $94 \%$ yield by heating at $50{ }^{\circ} \mathrm{C}$ for 24 hours and the sterically hindered 2-phenyl derivative, although required longer reaction times and higher temperature, led to $\mathbf{4 5}$ in $88 \%$ yield. Reaction of $\mathbf{1}$ with the bulky $N$-phenylpyrrole was achieved in even more drastic conditions affording the pyrrolylpyridazine $\mathbf{4 6}$ in only $23 \%$ yield while the electron-rich $\mathrm{N}$-(dimethylamino)pyrrole allowed to isolate $\mathbf{4 7}$ in 78\% yield (Scheme 15) [50]. DCP was also able to react with 1-(2-pyridyl)-2-propen-1-ol, acting as C-3 carbon nucleophile, to give the polyfunctionalyzed derivative $\mathbf{4 8}$ by replacement of a CN group (Scheme 16) [51].

Scheme 16. $\mathrm{S}_{\mathrm{N}} \mathrm{Ar} 2$ reactions of DCP with 1-(2-pyridyl)-2-propen-1-ol and amines.<smiles>N#Cc1cnncc1CCC(=O)c1ccccn1</smiles><smiles>C=CC(O)c1ccccn1</smiles><smiles>N#Cc1cnncc1C#N</smiles>

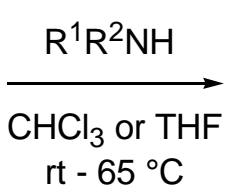<smiles>[R][X]c1cnncc1C#N</smiles>

49 48-100\%

Moreover, on the basis of the reactivity observed with carbon nucleophiles, the behavior of DCP towards other nucleophilic species was also studied. In particular, some preliminary results concerning reactions with amines evidenced a facile access to aminocyanopyridazines 49 , promising for further synthetic elaborations (Scheme 16) [unpublished results]. 


\section{Synthetic applications}

\subsection{Synthesis of Phthalocyanine Analogues}

As previously reported, phthalocyanines have been the subject of intensive study due to their multipurpose applications as, for instance, dyes and pigments, photoconducting reagents, catalysts, deodorants, germicides, in the photodynamic therapy of cancer, and so on [52-54].

Scheme 17. Synthesis of phthalocyanine analogues.

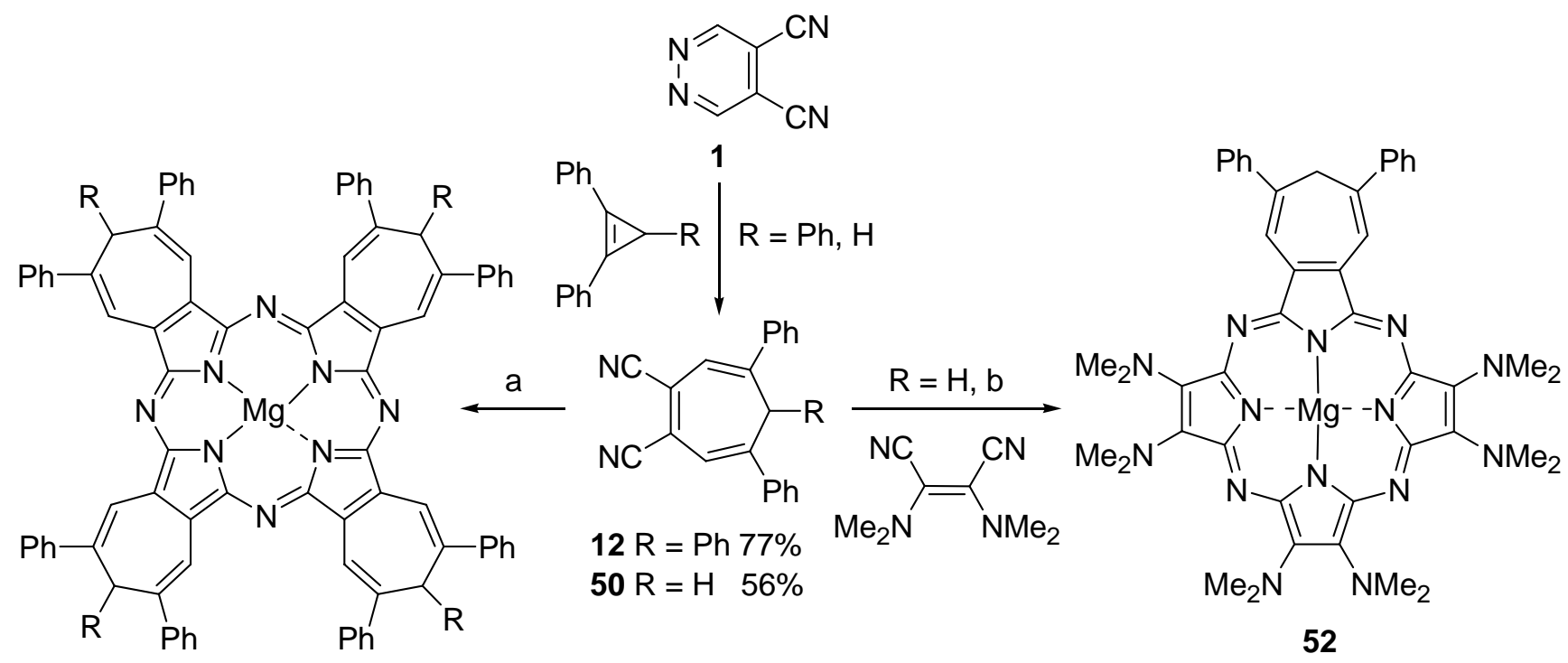

51a,b R = Ph, H

a: $\mathrm{Mg}(\mathrm{OPr})_{2}, n-\mathrm{PrOH}$, reflux, 12-15 h; b: $\mathrm{Mg}(\mathrm{OBu})_{2}, n-\mathrm{BuOH}$, reflux, $24 \mathrm{~h}, 9 \%$<smiles>N#Cc1cnncc1C#N</smiles>

1<smiles>Nc1c(-c2ccccc2)c(C(=O)O)c(-c2ccccc2)c(-c2ccccc2)c1-c1ccccc1</smiles>

C

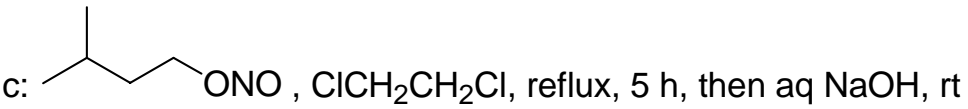

d: $\mathrm{DBU}, \mathrm{ZnCl}_{2}$, isopentanol, reflux, $40 \mathrm{~h}$, then $\mathrm{H}_{2} \mathrm{O}, 60^{\circ} \mathrm{C}, 30$ min<smiles>N#Cc1cc2c(-c3ccccc3)c(-c3ccccc3)c(-c3ccccc3)c(-c3ccccc3)c2cc1C#N</smiles>

$5330 \%$

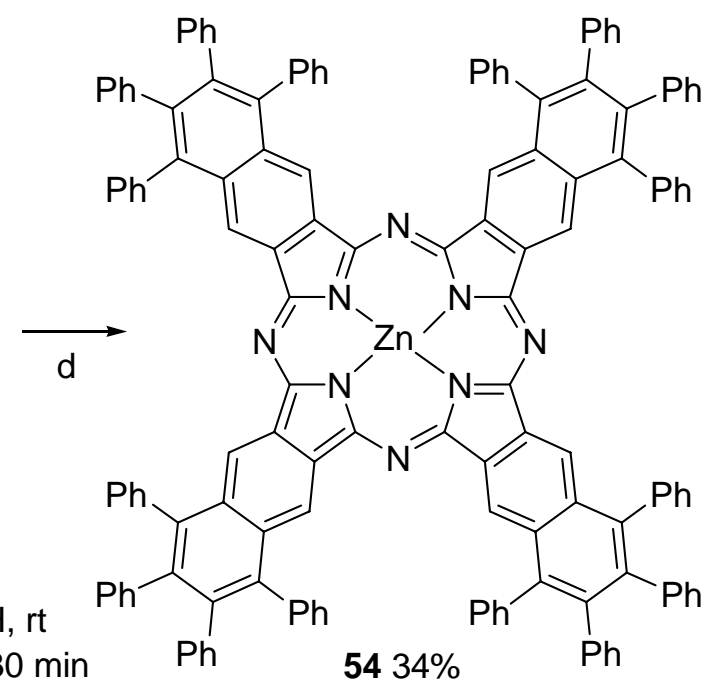

In this context, dicyanocycloheptatrienes 12 and 50, obtained by HDA reactions of DCP with 1,2,3triphenyl- and 1,2-diphenyl-cyclopropene, have been exploited for the synthesis of seven-membered carbon-ring-fused phthalocyanine analogue complexes 51a,b, in which the $\pi$ system changes during dehydrogenation/hydrogenation cycles, according with nonaromatic cycloheptatriene/aromatic tropylium cation interconversion (Scheme 17) [55]. 
Moreover, crossover Linstead macrocyclization of $\mathbf{1 2}$ and bis(dimethylamino)maleonitrile gave rise to an unsymmetrical $\left(\mathrm{A}_{3} \mathrm{~B}\right)$ aminoporphyrazine 52 converted by hydride abstraction into a tropyliumfused aminoporphyrazine, labelled as a 'push-pull' macrocycle for the presence of both electrondonating and electron-withdrawing groups (Scheme 17) [56].

On the other hand, diazotization of 3,4,5,6-tetraphenylanthranilic acid in the presence of DCP allowed HDA trapping of the aryne intermediate for the synthesis of dicyanonaphthalene $\mathbf{5 3}$, converted to the polyphenylated naphthalocyanine 54. The sixteen phenyl substituents, orthogonal to the macrocyclic plane, are responsible for improved solubility and minimal intermolecular aggregation (Scheme 17) [57].

\subsection{Synthesis of Enantiopure $C_{2}$ Symmetric bis(2-Oxazolinyl) Cage Ligands}

In the last decades, a great range of ligands containing one, two or three oxazoline rings has been successfully developed and applied in asymmetric catalysis [58]. In particular, the attention towards enantiopure $C_{2}$ symmetric bis(oxazoline) (Box) ligands has increased enormously and a large number of chiral ligands with a great deal of structural diversity has been synthesized and applied in an impressive variety of metal-catalyzed processes [59]. The synthesis of oxazoline systems can be easily achieved from amino alcohols and nitrile or carboxylic acid derivatives [60] and, in particular, Bolm et al. described a direct reaction of dinitriles with enantiomerically pure $\beta$-amino alcohols under zinc chloride catalysis [61]. On these grounds, the cage systems obtained by domino reactions of DCP with dienes, all containing a maleonitrile moiety coming from $\mathbf{1}$, appeared interesting substrates for the synthesis of new classes of chiral bis(oxazoline) ligands.

Scheme 18. Synthesis of mono- and bis(oxazoline) ligands.

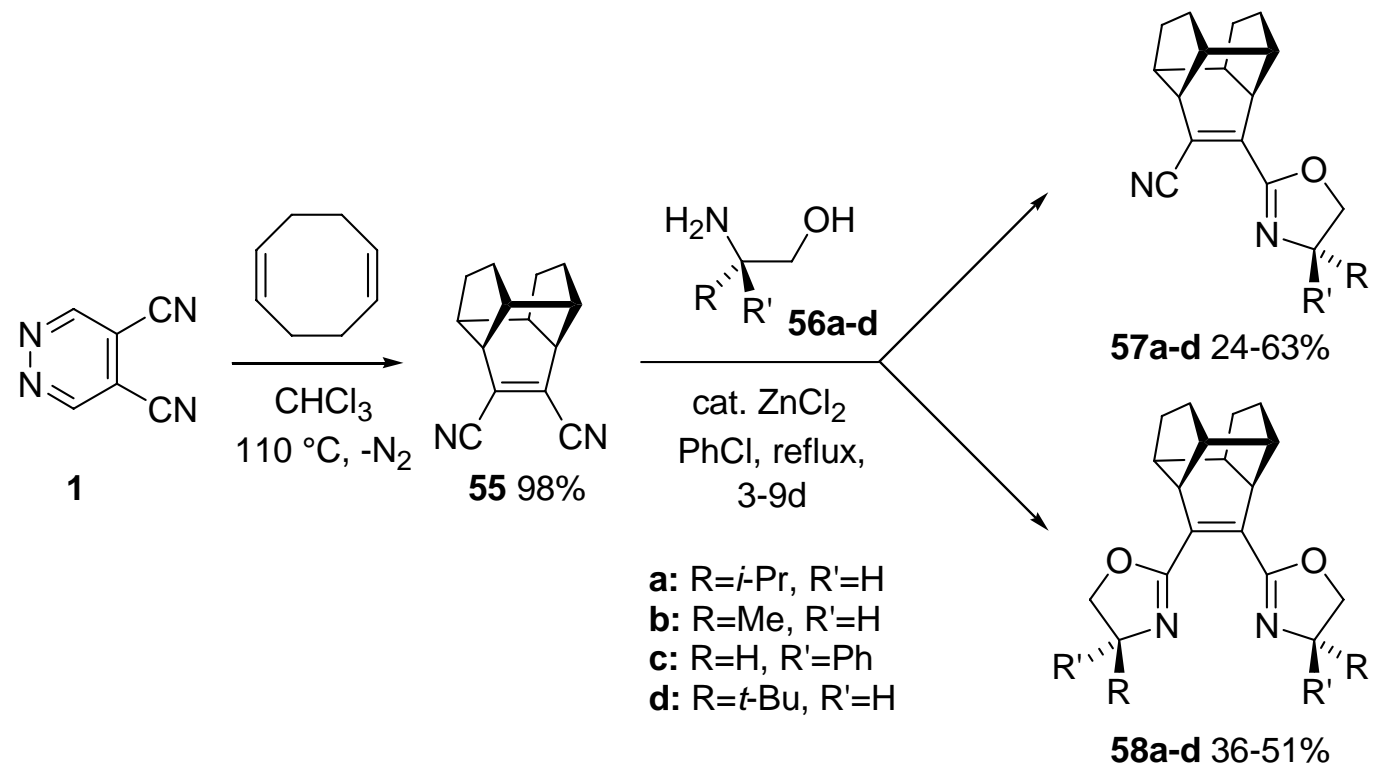

Then, the tetracyclic compound 55, prepared almost quantitatively from reaction of 1 with COD (Table 1 , entry 1 ), was allowed to react with enantiopure $\beta$-amino alcohols 56a-d in anhydrous chlorobenzene under reflux, in the presence of catalytic amounts of anhydrous $\mathrm{ZnCl}_{2}$. Depending on the experimental conditions, different quantities of enantiomerically pure mono(2-oxazolines) 57a-d 
and bis(2-oxazoline) (Cage-Box) ligands 58a-d were isolated from the reaction mixtures. Anyway, mono(oxazolines) can be converted into the bis(oxazoline) derivatives by treatment with $\beta$-amino alcohols in the previously reported conditions (Scheme 18) [62]. A 1:1 Zn(II) complex 59 was isolated in $99 \%$ yield by treatment of $\mathbf{5 8 a}$ with $\mathrm{ZnCl}_{2}$ and its molecular structure determined by single-crystal $\mathrm{X}$-ray diffraction analysis (Figure 2).

Figure 2. ORTEP drawing of complex 59.

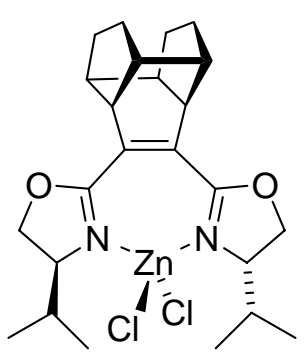

59

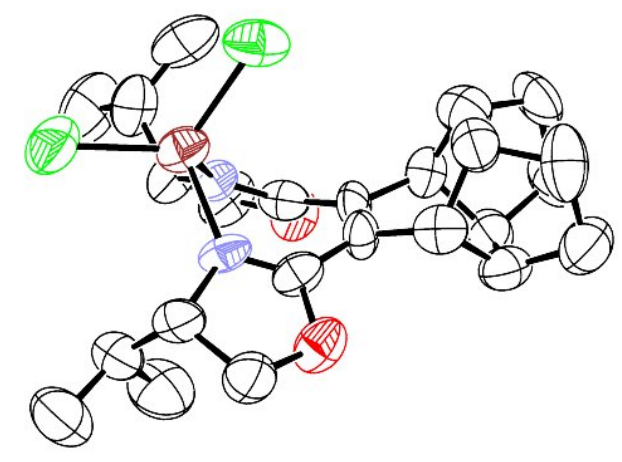

\section{Conclusions}

These results clearly evidence for 4,5-dicyanopyridazine a polyvalent reactivity towards different species. In fact, although electron-deficient pyridazines, and especially symmetric derivatives [63], appeared quite inert in inverse electron-demand HDA reactions, DCP exhibited an exceptional behavior as heterocyclic azadiene able to react not only with electron-rich dienophiles but also with unactivated alkenes and alkynes, as well as electron-poor $2 \pi$ electron counterparts. In addition to the synthesis of dicyanocyclohexa-1,3-dienes, a general and complementary methodology for a facile access to substituted phthalonitriles through reactions with alkynes and enamines was accomplished. Moreover, pericyclic three-step homodomino processes with bis-dienophiles allowed to realize a general strategy for the one-pot synthesis of carbo- and hetero-cage systems.

Pyrrole and indole derivatives reacted in different ways with DCP. In particular, it appears possible to modulate the reaction course by changing the experimental conditions. By simple heating at 110-150 ${ }^{\circ} \mathrm{C}$ in chloroform or xylene (sealed tube), HDA reactions afforded dicyano-indoles and -carbazoles via direct benzoannelations. On the other hand, operating in acetic acid in milder conditions $\left(25-110^{\circ} \mathrm{C}\right)$, DCP was able to react with the same species as a very reactive heterocyclic electrophile at C-4 carbon in formal $\mathrm{S}_{\mathrm{N}} \mathrm{Ar} 2$ processes where a $\mathrm{CN}$ group acts as leaving group. Mechanistic investigations evidenced that cyanopyrrolyl- and cyanoindolyl-pyridazines, obtained in satisfactory yields, are the fruit of addition-elimination processes. Synthetic applications of the above reaction products were also observed in different domains.

In conclusion, the exceptional reactivity of DCP compared to other electron-poor pyridazines, mainly evidenced in HDA reactions, could be likely ascribed to the lack of any steric hindrance experienced by the approaching reagents. On this ground, the 'flat' 4,5-dicyanopyridazine could 
certainly be welcome in the fantastic 'Flatland' country that in 1882 the London Reverend Edwin A. Abbott described in his book.

\section{Acknowledgements}

We would like to thank Rodolfo Nesi for his decisive contribution to the realization of this research and all the students that with their efforts, enthusiasm, and dedication allowed to perform and develop the synthetic work. Moreover, we thank B. Innocenti and M. Passaponti for technical assistance and Ministry of University and Research (MIUR Rome-Italy) for financial support.

\section{References}

1. Tišler, M.; Stanovnik, B. Pyridazines and their Benzo Derivatives. In Comprehensive Heterocyclic Chemistry; Boulton, A.J., McKillop, A., Eds.; Pergamon: Oxford, UK, 1984; Volume 3, pp. 1-56.

2. Coates, W.J. Pyridazines and their Benzo Derivatives. In Comprehensive Heterocyclic Chemistry II; Boulton, A.J., Ed.; Pergamon: Oxford, UK, 1996; Volume 6, pp. 1-91.

3. Maes, B.U.W.; Lemière, G.L.F. Pyridazines and their Benzo Derivatives. In Comprehensive Heterocyclic Chemistry III, Aitken, A., Ed.; Elsevier: Oxford, UK, 2008; Volume 8, pp. 1-116.

4. Di Stefano, L.; Castle, R.N. The synthesis of pyridazino[4,5-d]pyridazines, pyrazino [2,3-d] pyridazines and a pyrimido [4,5-d] pyridazine. J. Heterocycl. Chem. 1968, 5, 53-59.

5. Heinisch, G.; Lötsch, G. Pyridazines XXIV. Application of Radicalic ethoxycarbonylation to the synthesis of pyridazine mono- and polycarboxylic acid esters. Tetrahedron 1985, 41, 1199-1205.

6. Minisci, F. Novel applications of free-radical reactions in preparative organic chemistry. Synthesis 1973, 1-24.

7. Minisci, F.; Fontana, F.; Vismara, E. Substitutions by nucleophilic free radicals: A new general reaction of heteroaromatic bases. J. Heterocycl. Chem. 1990, 27, 79-96.

8. Neunhoeffer, H.; Werner, G. Reaktion von pyridazincarbonestern mit 1-diäthylaminopropin. Tetrahedron Lett. 1972, 13, 1517-1518.

9. Neunhoeffer, H.; Werner, G. Reaktion von pyridazinen mit 1-diäthylaminopropin. Liebigs Ann. Chem. 1973, 437-442.

10. Neunhoeffer, H.; Werner, G. Reaktion von pyridazinen mit 1-methoxy- $N, N$-dimethylvinylamin. Liebigs Ann. Chem. 1973, 1955-1962.

11. Jojima, T.; Takeshiba, H.; Konotsune, T. Pyridazines I. Novel intramolecular cycloaddition of 3chloro-6-(2-allylphenoxy)pyridazines. Chem. Pharm. Bull. 1973, 20, 2191-2203.

12. Boger, D.L. Diels-Alder reactions of azadienes. Tetrahedron 1983, 39, 2869-2939.

13. Boger, D.L. Diels-Alder reactions of heterocyclic azadienes: Scope and applications. Chem. Rev. 1986, 86, 781-793.

14. Boger, D.L.; Weinreb, S.N. Heteroaromatic Azadienes. In Hetero Diels-Alder methodology in organic synthesis, Wasserman, H.H., Ed.; Academic: San Diego, CA, USA, 1987; pp. 300-357.

15. Boger, D.L.; Patel, M. Recent applications of the inverse electron demand Diels-Alder reaction. Progr. Heterocycl. Chem. 1989, 1, 30-64. 
16. Benson, S.C.; Gross, J.L.; Snyder, J.K. Indole as a Dienophile in Inverse Electron Demand DielsAlder Reactions: Reactions with 1,2,4-Triazines and 1,2-Diazines. J. Org. Chem. 1990, 55, 3257-3269.

17. Lantos, I.; Sheldrake, P.W.; Wells, A.S. Novel cage compounds from inter- and intra-molecular Diels-Alder reactions of heteroaromatic azadienes and methyl coumalate with cyclo-octa-1,5diene. J. Chem. Soc. Perkin Trans. 1 1990, 1887-1890.

18. Neunhoeffer, H. 1,2,4-Triazines and their Benzo Derivatives. In Comprehensive Heterocyclic Chemistry, Boulton, A.J., McKillop, A., Eds.; Pergamon: Oxford, UK, 1984; Volume 3, pp. 422-429.

19. Neunhoeffer, H. Tetrazines and Pentazines. In Comprehensive Heterocyclic Chemistry, Boulton, A.J., McKillop, A., Eds.; Pergamon: Oxford, UK, 1984; Volume 3, pp. 550-555.

20. Neunhoeffer, H. 1,2,4-Triazines and their Benzo Derivatives. In Comprehensive Heterocyclic Chemistry II, Boulton, A.J., Ed.; Pergamon: Oxford, UK, 1996; Volume 6, pp. 533-538.

21. Sauer, J. 1,2,4,5-Tetrazine. In Comprehensive Heterocyclic Chemistry II, Boulton, A.J., Ed.; Pergamon: Oxford, UK, 1996; Volume 6, pp. 912-944.

22. Van der Plas, H.C. Cycloalkenopyridines by ring transformations of diazines and triazines. ARKIVOC 2008, (iii), 127-139.

23. Saracoglu, N. Recent advances and applications in 1,2,4,5-tetrazine chemistry. Tetrahedron 2007, 63, 4199-4236.

24. Nesi, R.; Giomi, D.; Turchi, S. [4+2]- and [2+4]-Cycloaddition processes of 4,5dicyanopyridazine with 2,3-dimethylbuta-1,3-diene. Tetrahedron 1994, 50, 9189-9194.

25. Tietze, L.F. Domino reactions in organic synthesis. Chem. Rev. 1996, 96, 115-136.

26. Winkler, J.D. Tandem Diels-Alder cycloadditions in organic synthesis. Chem. Rev. 1996, 96, 167-176.

27. Adembri, G.; De Sio, F.; Nesi, R.; Scotton, M. Synthesis and properties of 1,4dimethylpyridazino[4,5-d] pyridazines. J. Heterocycl. Chem. 1975, 12, 95-99.

28. Giomi, D.; Nesi, R.; Turchi, S.; Coppini, R. Tandem inverse electron-demand Diels-Alder reactions of 4,5-dicyanopyridazine with nonconjugated dienes: An excellent direct entry into carbo- and hetero-cage systems. J. Org. Chem. 1996, 61, 6028-6030.

29. Giomi, D.; Nesi, R.; Turchi, S.; Mura, E. Polyfunctionalized cage compounds by pericyclic domino processes of 4,5-dicyanopyridazine with dienes: Applications and limits. J. Org. Chem. 2000, 65, 360-364.

30. Nesi, R.; Giomi, D.; Turchi, S.; Falai, A. 4,5-Dicyanopyridazine: A 1,2-diazine superheterodiene for [4+2] cycloaddition reactions. J. Chem. Soc. Chem. Commun. 1995, 2201-2202.

31. Turchi, S.; Giomi, D.; Capaccioli, C.; Nesi, R. Hetero Diels-Alder reactions of 4,5dicyanopyridazine with alkenes. Tetrahedron 1997, 53, 11711-11720.

32. Turchi, S.; Nesi, R.; Giomi, D. Reactions of 4,5-dicyanopyridazine with alkynes and enamines: A new straightforward complementary route to 4-mono- and 4,5-disubstituted phthalonitriles. Tetrahedron 1998, 54, 1809-1816.

33. Nesi, R.; Turchi, S.; Giomi, D.; Corsi, C. Phthalonitriles by hetero Diels-Alder reactions of 4,5dicyanopyridazine with enamines: Isolation and characterization of unprecedented intermediates. Tetrahedron 1998, 54, 10851-10856. 
34. Sundberg, R.J. Pyrroles and their Benzo Derivatives: (iii) Synthesis and Applications. In Comprehensive Heterocyclic Chemistry; Bird, C.W., Cheeseman, G.W.H., Eds.; Pergamon: Oxford, UK, 1984; Volume 4, pp. 313-376.

35. Sundberg, R.J. Pyrroles and their Benzo Derivatives: Synthesis. In Comprehensive Heterocyclic Chemistry II; Bird, C.W., Ed.; Pergamon: Oxford, UK, 1996; Volume 2, pp. 119-206.

36. Gribble, G.W. Recent developments in indole ring synthesis-methodology and applications. $J$. Chem. Soc. Perkin Trans. 1 2000, 1045-1075.

37. Jones, R.A. Pyrroles and their Benzo Derivatives: Reactivity. In Comprehensive Heterocyclic Chemistry, Bird, C.W., Cheeseman, G.W.H., Eds.; Pergamon: Oxford, UK, 1984; Volume 4, pp. 261-268.

38. Black, D.St.C. Pyrroles and their Benzo Derivatives: Reactivity. In Comprehensive Heterocyclic Chemistry II, Bird, C.W., Ed.; Pergamon: Oxford, UK, 1996; Volume 2, pp. 81-88.

39. Giomi, D.; Cecchi, M. Study on direct benzoannelation of pyrrole and indole systems by domino reactions with 4,5-dicyanopyridazine. Tetrahedron 2002, 58, 8067-8071.

40. Giomi, D.; Cecchi, M. Domino reactions of 4,5-dicyanopyridazine with dihydroheterocycles: Synthetic and mechanistic features. J. Org. Chem. 2003, 68, 3340-3343.

41. Huang, J.J. Synthesis of fused 1,2,4-triazines: 6- and 7-azapteridine and 6-azapurine ring systems. J. Org. Chem. 1985, 50, 2293-2298.

42. Ohba, S.; Konno, S.; Yamanaka, H. Studies on as-triazine derivatives. XVI. Reaction of 1,2,4triazinecarbonitriles with carbanions. Chem. Pharm. Bull. 1991, 39, 486-488.

43. Ozaki, K.; Yamada, Y.; Oine, T. Studies on 4(1H)-quinazolinones. III. Some derivatizations of 2ethoxycarbonylalkyl-1-substituted-4(1H)-quinazolinones. Chem. Pharm. Bull. 1983, 31, 2234-2243.

44. Hirano, H.; Lee, R.; Tada, M. The substitution reaction of pyrazine-2,3-dicarbonitrile derivatives with ammonia, amines, water and alcohols. J. Heterocycl. Chem. 1982, 19, 1409-1413.

45. Penney, J.M. Synthesis of aminopyridines via an unprecedented nucleophilic aromatic substitution of cyanopyridines. Tetrahedron Lett. 2004, 45, 2667-2669.

46. Landquist, J.K. Nucleophilic replacements in 4-cyanopyridinium salts. J. Chem. Soc. Perkin Trans. 1 1976, 454-456.

47. Haider, N.; Heinisch, G.; Moshuber, J. Pyridazines - 61. Unexpected reaction behavior of pyridazinecarbonitrile derivatives towards phenylmagnesium chloride. Tetrahedron 1991, 47, 8573-8578.

48. Hayashi, E.; Iinuma, M.; Utsunomiya, I.; Iijima, C.; Oishi, E.; Higashino, T. Grignard reactions, of 1-phthalazine-, 2-quinoxaline-, and 4-cinnoline-carbonitrile. Chem. Pharm. Bull. 1977, 25, 579-589.

49. Ames, D.E.; Bull, D. Preparation of cinnoline-3,4-dicarbonitrile and -dicarboxylic acid. Tetrahedron 1981, 37, 2489-2491.

50. Cecchi, M.; Micoli, A.; Giomi, D. Nucleophilic aromatic substitutions on 4,5-dicyanopyridazine. Pyrrole and indole systems as carbon nucleophiles. Tetrahedron 2006, 62, 12281-12287.

51. Giomi, D.; Piacenti, M.; Brandi, A. New reactivity of hydroxyallylpyridyl derivatives as C-3 carbon nucleophiles. Tetrahedron Lett. 2004, 45, 2113-2115. 
52. Leznoff, C.C.; Lever, A.B.P.; Phthalocyanines: Properties and Applications; VCH Publishers: New York, USA, 1989; Volumes 1-4.

53. Shirai, H.; Kobayashi, N. Phthalocyanines - Chemistry and Functions; IPC: Tokyo, Japan, 1997.

54. Tanaka, M. Phthalocyanines-High performance pigments and their applications. In High performance pigments, 2nd ed.; Faulkner, E.B., Schwartz, R.J., Eds.; Wiley-VCH: Weinheim, Germany, 2009; pp. 275-291.

55. Kobayashi, N.; Nonomura, T.; Nakai, K. A seven-membered carbon-ring-fused phthalocyanine analogue in which the $\pi$ system changes during dehydrogenation/hydrogenation cycles. Angew. Chem. Int. Ed. 2001, 40, 1300-1303.

56. Ruggiero, A.; Fuchter, M.J.; Kokas, O.J.; Negru, M.; White, A.J.P.; Haycock, P.R.; Hoffman, B.M.; Barrett, A.G.M. A 'push-pull' tropylium-fused aminoporphyrazine. Tetrahedron 2009, 65, 9690-9693.

57. Lee, C.H.; Sooksimuang, T.; Mandal, B.K. Synthetic methodology towards novel polyphenylated naphthalocyanines. J. Porphyr. Phthalocyanines 2006, 10, 135-139.

58. McManus, H.A.; Guiry, P.J. Recent developments in the application of oxazoline-containing ligands in asymmetric catalysis. Chem. Rev. 2004, 104, 4151-4202.

59. Desimoni, G.; Faita, G.; Jørgensen, K.A. $C_{2}$-Symmetric chiral bis(oxazoline) ligands in asymmetric catalysis. Chem. Rev. 2006, 106, 3561-3651.

60. Gant, T.G.; Meyers, A.I. The chemistry of 2-oxazolines (1985-present). Tetrahedron 1994, 50, 2297-2360.

61. Bolm, C.; Weickhardt, K.; Zehnder, M.; Ranff, T. Synthesis of optically active bis(2-oxazolines): Crystal structure of a 1,2-bis(2-oxazolinyl)benzene zinc chloride complex. Chem. Ber. 1991, 124, 1173-1180.

62. Cecchi, M.; Faggi, C.; Giomi, D. New enantiopure $C_{2}$ symmetric bis(2-oxazolinyl)cage (CageBox) ligands from 4,5-dicyanopyridazine. Tetrahedron Asymmetry 2005, 16, 3998-4003.

63. Ho, T.L. Symmetry: A Basis for Synthesis Design; Wiley: New York, NY, USA, 1995; p.474.

(C) 2010 by the authors; licensee Molecular Diversity Preservation International, Basel, Switzerland. This article is an open-access article distributed under the terms and conditions of the Creative Commons Attribution license (http://creativecommons.org/licenses/by/3.0/). 